OPEN ACCESS

Edited by:

Zhong-Qiu Liu,

Guangzhou University of Chinese

Medicine, China

Reviewed by:

Wei Dong Chen,

Anhui University of Chinese Medicine,

China

Yudong Liu,

Peking University People's Hospital,

China

*Correspondence:

Changgang Sun

scgdoctor@126.com

Wenwei Zhu

wwz3006@163.com

${ }^{t}$ These authors have contributed equally to this work

Specialty section:

This article was submitted to

Ethnopharmacology,

a section of the journal

Frontiers in Pharmacology

Received: 29 May 2021

Accepted: 20 August 2021

Published: 03 September 2021

Citation:

Yin $Q$, Wang $L$, Yu $H$, Chen $D$, Zhu W and Sun $C$ (2021) Pharmacological Effects of Polyphenol Phytochemicals on the JAK-STAT Signaling Pathway.

Front. Pharmacol. 12:716672.

doi: 10.3389/fphar.2021.716672

\section{Pharmacological Effects of Polyphenol Phytochemicals on the JAK-STAT Signaling Pathway}

\author{
Qianqian Yin ${ }^{1 \dagger}$, Longyun Wang ${ }^{1 \dagger}$, Haiyang $\mathrm{Yu}^{2}$, Daquan Chen ${ }^{3}$, Wenwei Zhu ${ }^{4 \star}$ and \\ Changgang Sun ${ }^{5,6 *}$
}

${ }^{1}$ College of Traditional Chinese Medicine, Shandong University of Traditional Chinese Medicine, Jinan, China, ${ }^{2}$ State Key Laboratory of Component-based Chinese Medicine, Tianjin University of Traditional Chinese Medicine, Tianjin, China, ${ }^{3}$ School of Pharmacy, Yantai University, Yantai, China, ${ }^{4}$ Yueyang Hospital of Integrated Traditional Chinese and Western Medicine, Shanghai University of Traditional Chinese Medicine, Shanghai, China, ${ }^{5}$ Department of Oncology, Weifang Traditional Chinese Hospital, Weifang, China, ${ }^{6}$ Qingdao Academy of Chinese Medical Sciences, Shandong University of Traditional Chinese Medicine, Qingdao, China

The JAK-STAT signaling pathway is a common pathway of many cytokine signal transductions, closely related to cell proliferation, apoptosis, differentiation, and inflammatory response. It is essential for inhibiting the inflammatory response, initiating innate immunity, and coordinating adaptive immune mechanisms. Owing to the nature of this pathway and its potential cross-epitopes with multiple alternative pathways, the longterm efficacy of monotherapy-based adaptive targeting therapy is limited, and the majority of drugs targeting STATs are still in the preclinical phase. Meanwhile, curcumin, quercetin, and several kinds of plant polyphenol chemicals play roles in multiple sites of the JAK-STAT pathway to suppress abnormal activation. Polyphenol compounds have shown remarkable effects by acting on the JAK-STAT pathway in anti-inflammatory, antitumor, and cardiovascular disease control. This review summarizes the pharmacological effects of more than 20 kinds of phytochemicals on JAK-STAT signaling pathway according to the chemical structure of polyphenolic phytochemicals.

Keywords: JAK, STAT, signaling pathway, polyphenols, phytochemicals

\section{INTRODUCTION}

The Janus kinase (JAK)/signal transducer and activator of transcription (STAT) signaling pathway is a simple membrane-to-nucleus signaling pathway (O'Shea et al., 2015), used by quantities of cytokines, growth factors, and interferons, and extracellular factors also regulate gene expression through this pathway. It is the fundamental paradigm for cells to sense environmental cues and interpret these signals to regulate cell growth and differentiation, and is extensively involved in cell differentiation, proliferation, apoptosis, and inflammatory response processes (Yang et al., 2020b). Numerous experiments have shown the JAK-STAT pathway to be abnormally activated in rheumatoid arthritis (RA), Parkinson's disease, multiple sclerosis, inflammatory bowel disease, sepsis, and development of tumors (Westhovens et al., 2017). Because of the role of the JAK-STAT signals in the universality of autoimmune diseases and malignancies, targeting the JAK-STAT pathway to initiate a congenital immune response, coordinated adaptive immunity, and to inhibit inflammation is crucial.

The intracellular components of the cytokine signaling pathway, especially the JAK family of nonreceptor tyrosine kinases that transmit signals, can be used as key targets to inhibit the effects of 
various cytokines. A variety of JAK inhibitors, such as baricitinibde, tofacitinib, and ruxolitinib, have been approved by the United States Food and Drug Administration for the treatment of RA and psoriatic arthritis (PSA) (T Virtanen et al., 2019). However, multiple adverse reactions of JAK inhibitors have also been reported. All the JAK inhibitors, except filgotinib, reduce natural killer cells. Almost all JAK inhibitors increase the incidence of herpes zoster, while baricitinib and upadacitinib increase the risk of venous thromboembolism (Reddy and Cohen, 2020). Although STATs are abnormally activated in malignancies and immune-related diseases, it is more challenging as a therapeutic target than JAKs because of its lack of enzyme activity, bioavailability, in vivo efficacy, and selectivity (Schwartz et al., 2016). STAT3 is the important member of the STAT family that has been the focus of therapeutic attempts (except for Fludarabine, which targets STAT1), but the majority of drugs targeting STATs are still in the preclinical phase. Three therapeutic strategies are currently being used by targeting the upstream and downstream STAT activation: 1) inhibitory peptides, which sequester STATs from upstream receptors and kinases, 2) small-molecule inhibitors, which impede STAT activation and/or function, and 3) decoy oligonucleotides, which sequester STATs away from genomic binding sites (Hayakawa et al., 2013).

Phytochemicals are widely used in the treatment of diseases due to their multi-target effects, among which polyphenolic phytochemicals have been frequently reported to interfere with cell proliferation, apoptosis, differentiation and inflammation by acting on multiple sites in the JAK-STAT pathway. Polyphenols are a class of complex secondary metabolites with multiple phenolic hydroxyl groups, which are commonly found in tea, fruits, and vegetable substrates. According to the number of phenolic rings they contain, they can be roughly divided into flavonoids (flavones, flavonols, isoflavones, anthocyanidins, flavanones, flavanols, chalcones, and biflavones), phenolic acids, stilbenes, lignans and some compounds with complex parent nuclei, such as Curcumin and Wedelolactone (Yi et al., 2019). Most polyphenol phytochemicals have antioxidant, antiinflammatory, and antitumor effects, and inhibit cardiovascular diseases (Sun et al., 2019a). Multiple polyphenolic phytochemicals inhibit abnormal activation and reduce resistance to targeted drugs by acting on multiple sites. In order to make a systematic summary of polyphenols phytochemicals, this paper reviews the pharmacological effects of more than 20 polyphenols on the JAK-STAT signaling pathway.

\section{JAK-STAT SIGNALING PATHWAY Composition and Transmission of JAK-STAT Signaling Pathway JAK}

JAKs are a family of nonreceptor tyrosine kinases in cells, consisting of four members: JAK1, JAK2, JAK3, and Tyk2 (Kurdi et al., 2012). The JAK protein family mediates the signal transduction of various hormones and cytokines, such as growth hormones, immune system regulators, and hematopoietic factors (Xin et al., 2020). The JAK protein family is structurally composed of seven JAK homology (JH) domains, the classical protein tyrosine kinase domain (JH1); the pseudokinase domain (JH2); the Src-homology type 2 (SH2) domain (JH3-JH5), and the FERM domain (JH6-JH7) (Garrido-Trigo and Salas, 2020). Although JAK3 is mainly expressed in hematopoietic cells, the other three members are thought to be universally expressed in tissues. JAK does not only phosphorylate the bound cytokine receptor but also phosphorylates multiple $\mathrm{SH} 2$ domain-specific signaling molecules (Agrawal et al., 2011).

\section{STAT}

The STAT family is a class of cytoplasmic proteins that can bind to the DNA in the regulatory region of target genes and are downstream targets of JAK (Xu et al., 2019). The STAT family consists of the following members: STAT1-STAT6; STAT5 includes STAT5A and STAT5B. The STAT proteins can be structurally divided into five main domains: N-terminal conserved sequence, DNA binding domain, SH3 domain, SH2 domain, and C-terminal transcriptional activation domain (Chang et al., 2018b). STATs bind to DNA regulatory elements, and direct the transcription of mRNAs or long noncoding RNAs.

\section{Activation and Inhibition of the JAK-STAT Pathway}

Under normal physiological conditions, the STAT protein exists in the cytoplasm in an inactive form or is briefly activated (Bodmer et al., 2020). A variety of cytokines attach to type I/II cytokine receptors to dimerize the receptors. The tyrosine residue on the receptor aggregates with JAK (Stokes et al., 2015). The surrounding JAKs are activated by phosphorylation of each other, and the activated JAK protein phosphorylates itself and these tyrosine residues, providing a docking site for the $\mathrm{SH} 2$ domain of the STAT protein (Ashrafizadeh et al., 2020). Phosphorylation induces the dimerization of STAT by the conserved SH2 domain, which then allows it to enter the nucleus via the $\alpha-5$ and RAN nuclear input pathways (Ramalingam et al., 2017).

The JAK-STAT signaling pathway is negatively regulated by three endogenous inhibitors: suppressor of cytokine signaling (SOCS), PTPs, and the protein inhibitors of activated STATs (PIAS). SOCS inhibit JAK activity, promote proteasomal degradation of JAK, and compete with STATs to bind to the cytokine receptors (Byers et al., 2009). PTPs induces STAT inactivation either by dephosphorylation of STAT proteins or by targeting associated receptor kinase complexes. It has been proved that the PIAS protein family consists of at least five members, and structurally contains four common domains, including one N-terminal SAP domain. Different members of the PIAS family can reduce the transcriptional activity of STAT and inhibit the binding of STAT to DNA (Shuai, 2000) (Figure 1).

\section{Relationship Between JAK-STAT Mutation and Disease}

In 2003, the first confirmed case of a mutation in the JAK-STAT pathway, a homozygous mutation in the STAT5B gene, was 


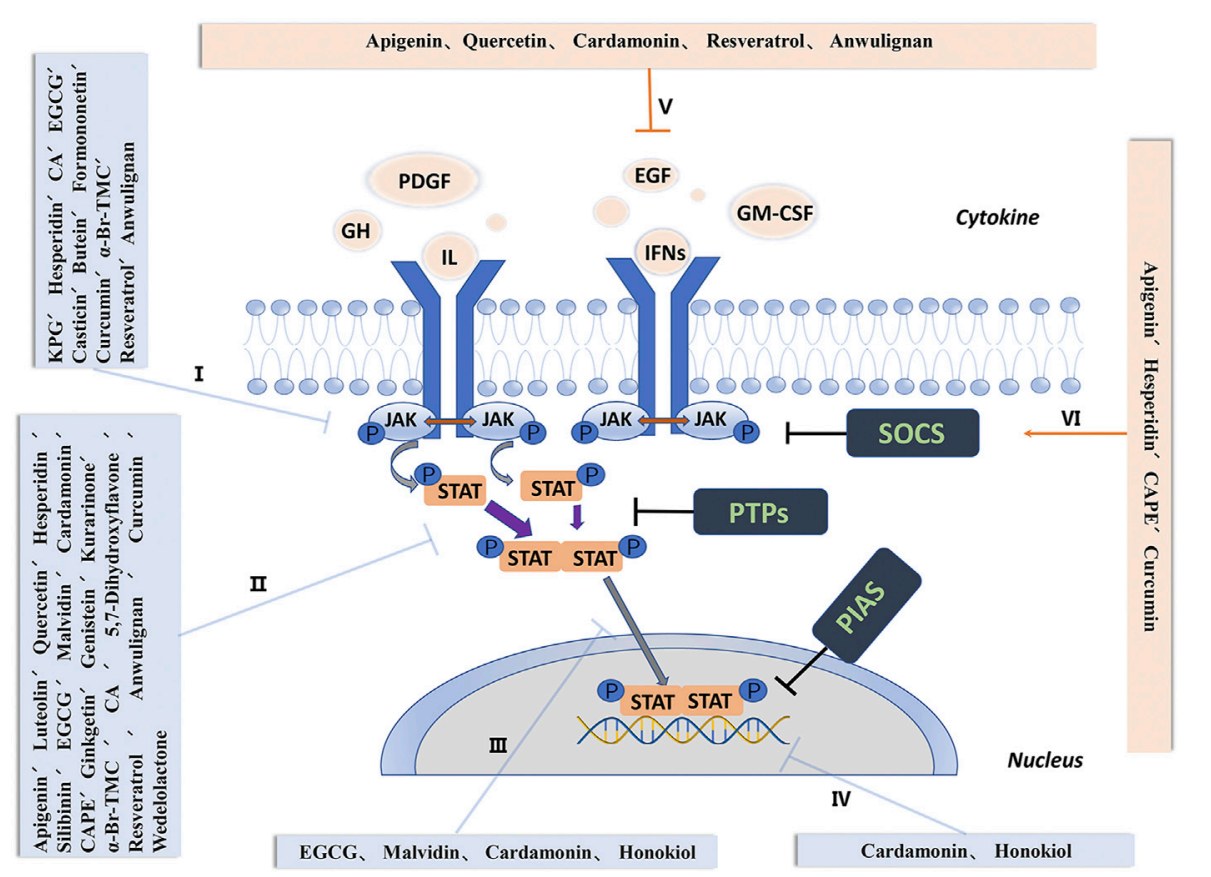

FIGURE 1 | Activation and negative regulation of the JAK-STAT signaling pathway. I, Inhibit activation and phosphorylation of JAK. II, Inhibit the activation, phosphorylation and formation of dimers of STAT. III, Interfere with the transfer of STAT to the nucleus. IV, Interfere with the binding of STAT and DNA and regulate the expression of STAT target genes. V, Up-regulate the secretion and expression of negative feedback signal SOCS. VI, Inhibit the secretion of interleukin, interferon, tumor necrosis factor and binding to receptors. Abbreviations: GH, growth hormone; PDGF, platelet-derived growth factor; EGF, epidermal growth factor; IFNs, interferons; IL, interleukins; GM-CSF, granulocyte-macrophage colony-stimulating factor; JAK, janus kinase; STAT, signal transducer and activator of transcription; SOCS, suppressor of cytokine signaling; PTPs, protein tyrosine phosphatases; PIAS, protein inhibitors of activated STATs.

reported, resulting in IGF-1 deficiency and insensitivity to growth hormone. After birth, the patient had abnormal growth, facial deformities, and significantly reduced acidlabile subunit (Kofoed et al., 2003). Several diseases were subsequently found to be associated with known JAKs and STATs mutations, and JAK-STAT dysfunction is commonly attributed to Loss-of-function (LOF) and Gain-of-function (GOF) mutations that may trigger the disease (Villarino et al., 2020) (Table 1). It was proven that GOF mutations in JAK1, JAK2, and JAK3 are responsible for hematopoietic disorders such as essential thrombocytopenia, acute myeloid leukemia, or Hodgkin Lymphoma. STAT1 and STAT2 play an important role in antitumor immune responses. STAT3 and STAT5 are associated with tumor genesis and progression, and STAT3, in particular, is closely associated with tumor cell survival, immunosuppression, and persistent inflammation (Villarino et al., 2020).

\section{PHARMACOLOGICAL EFFECTS OF POLYPHENOL PHYTOCHEMICALS ON THE JAK-STAT SIGNALING PATHWAY}

\section{Flavonoids}

Flavonoids are polyphenols found in plants with a broad spectrum of biological activities (Guan and Liu, 2016). They widely exist in fruits, vegetables, tea, cereals, and other plants, and belong to plant secondary metabolites. Flavonoids generally refer to a series of compounds consisting of two benzene rings (A and $\mathrm{B}$ rings) with phenolic hydroxyl groups connected to each other through three central carbon atoms (Li et al., 2020a). According to the oxidation degree of the central three-carbon chain (whether the 2,3-position is a double bond, whether the 4position is a carbonyl group), the connection position of the B-ring (2-or 3-position) and whether the three-carbon chain forms a ring, flavonoids can be divided into the following categories: Compounds with 2,3-position double bond and 4position carbonyl group are flavones; compounds with hydrogenated 2,3-position are flavanonols; compounds with 4-position carbonyl group reduction are flavanols; compounds with $\mathrm{B}$ ring at 3-position are isoflavones; and compounds with $\mathrm{C}$ ring opening ring are chalcones (Khokra et al., 2016). In addition, there are still some flavonoids have a unique mother nucleus structure, such as xanthones, aurones, pterocarpins. In plants, most of them combine with sugars to form glycosides, and some exist in free form. A number of in vitro studies have shown that flavonoids can inhibit the abnormal activation of the JAK-STAT pathway, and have outstanding medicinal value with anti-inflammatory, antioxidant, anticancer, antidepressant and antimicrobial properties, and are often used to prevent and treat cardiovascular and cerebrovascular diseases, for immune regulation, and liver protection. In addition, flavonoids have similar effects to phytoestrogens. 
TABLE 1 | JAK-STAT mutations and resulting disorders.

Mutations of JAK

\begin{tabular}{|c|c|c|}
\hline JAKs & Disease & References \\
\hline \multirow[t]{7}{*}{ JAK1 } & Atypical mycobacterial & O'Shea et al. (2013) \\
\hline & Solid neoplasms & Li and Chen (2021) \\
\hline & Bronchopneumonia & He and Tian (2021) \\
\hline & Liver inflammation & Daryadel et al. (2021) \\
\hline & Rheumatoid Arthritis (RA) & Westhovens et al. (2017) \\
\hline & Atopic dermatitis (AD) & Kim et al. (2020) \\
\hline & Diabetic nephropathy (DN) & Tuttle et al. (2018) \\
\hline \multirow[t]{5}{*}{ JAK2 } & Lymphoma & Van Den Neste et al. (2018) \\
\hline & Aorta aneurysm & Elf $(2021)$ \\
\hline & Esophageal squamous cell carcinoma (ESCC) & Li et al. (2021) \\
\hline & Pulmonary hypertension (PAH) & Leopold (2021) \\
\hline & Atopic dermatitis (AD) & Kim et al. (2020) \\
\hline \multirow[t]{2}{*}{ JAK3 } & Severe combined immunodeficiency (SCID) & O'Shea et al. (2013) \\
\hline & Leukemia & Tefferi (2008) \\
\hline \multirow[t]{2}{*}{ TYK2 } & Immunodeficiency. & Casanova et al. (2012) \\
\hline & Mycobacterium infection & Minegishi et al. (2006) \\
\hline \multicolumn{3}{|c|}{ Mutations of STAT } \\
\hline STATs & Disease & References \\
\hline \multirow[t]{3}{*}{ STAT1 } & Autoimmune disease (AID) & Patel et al. (2018) \\
\hline & Chronic myelogenous leukemia (CML) & Noguchi et al. (2018) \\
\hline & Candidiasis (CMC) & Zheng et al. (2015) \\
\hline \multirow[t]{2}{*}{ STAT2 } & Viral susceptibility & Moens et al. (2017) \\
\hline & Ahronic myelogenous leukemia (CML) & Takahashi et al. (2018) \\
\hline \multirow[t]{6}{*}{ STAT3 } & Hyperimmunoglobulin E syndrome & Mohr et al. (2013) \\
\hline & Leukemia & Barilà et al. (2020) \\
\hline & Lymphoma & Reilley et al. (2018) \\
\hline & Solid neoplasms & Yuan et al. (2020) \\
\hline & Inflammation & Ni et al. (2017) \\
\hline & Sjogren syndrome (SS) & Aota et al. (2021) \\
\hline \multirow[t]{5}{*}{ STAT4 } & Sjogren syndrome (SS) & Korman et al. (2008) \\
\hline & Kaposis sarcoma (KS) & Aavikko et al. (2015) \\
\hline & Rheumatoid arthritis (RA) & Yang et al. (2020a) \\
\hline & Systemic lupus erythematosus (SLE) & Patel et al. (2018) \\
\hline & Systemic sclerosis (SSC) & Xu et al. (2016) \\
\hline \multirow[t]{6}{*}{ STAT5A/B } & Leukemia & Dumas et al. (2019) \\
\hline & Lymphoma & Zhang et al. (2019) \\
\hline & Systemic lupus erythematosus (SLE) & Wu et al. (2017) \\
\hline & Eosinophilia & Kagami et al. (2000) \\
\hline & Solid neoplasms & Li et al. (2020b) \\
\hline & Inflammation & Surbek et al. (2021) \\
\hline \multirow[t]{2}{*}{ STAT6 } & Lymphoma & Yang et al. (2009) \\
\hline & Allergic inflammation & Ghaffar et al. (2000) \\
\hline
\end{tabular}

\section{Flavones}

Apigenin

Apigenin is a plant-derived flavonoid that is abundant in celery, plantain seed, and is effective in the prevention and treatment of prostate cancer, and in inhibiting tumorigenesis and angiogenesis in melanoma, breast, skin, and colon cancers. Apigenin reduces $\mathrm{p}$-JAK1/2 and $\mathrm{p}$-STAT3 in breast cancer (BT-474) cells, and demonstrates anticancer activity by inhibiting JAK-STAT (Ozbey et al., 2018). Programmed death in colon cancer cells can be induced by inhibition of STAT3 phosphorylation, thereby downregulating the antiapoptotic proteins Bcl-XL and Mcl-1 (Maeda et al., 2018). Apigenin can suppress the levels of IL-4, IL-5, IL-13, and IFN-g in Ovalbumin-Induced Allergic Rhinitis mouses Nasal lavage fluid (NLF) and inhibit the expression of p-STAT6 and SOCS1 (Chen et al., 2020). 


\section{Luteolin}

Luteolin is a secondary plant metabolite that belongs to flavonoids and is widely distributed in honeysuckle, Perilla, pepper and other herbs and vegetables, mainly in the form of glycosides in plants; luteolin inhibits epithelial-mesenchymal transition (EMT) and matrix metalloproteinase (MMP) secretion likely through deactivation of STAT3 signaling, to directly reduce the phosphorylation level of STAT3 in cancerous cells of pancreas, and inhibits IL-6 to reduce the invasion of pancreatic cancer cells (Huang et al., 2015). Luteolin has a synergistic effect with paclitaxel, which can effectively reduce p-STAT3 in mouse breast cancer cells and induce breast tumor regression in mice injected subcutaneously with MDAMB-231 cells together with paclitaxel (Yang et al., 2014). Luteolin also disrupts Hsp90 and STAT3 expression in gastric cancer cells. Luteolin activates SHP-1, a protein tyrosine phosphatase that dephosphorylates STAT3, and reduces the expression of its target genes, which "shut down" the regulation of target genes by inhibiting nuclear accumulation of STAT proteins, thereby demonstrating the efficacy of luteolin in inducing tumor growth inhibition in vivo (Song et al., 2017a).

\section{Flavonols}

\section{Kaempferol 7-O- $\beta$-D-glucoside}

KPG is a natural flavonol isolated from Hostaplantaginea (Lam.) Aschers with anti-cancer and anti-inflammatory effects (Tian et al., 2005), which inhibits p-STAT1 and p-STAT3 by inactivating $\mathrm{p}$-JAK1/2 in lipopolysaccharide-induced inflammation. Inactivation of STAT1/3 in macrophages inhibits the expression of lipopolysaccharide (LPS)-induced pro-inflammatory mediators, and attenuates the JAK-STAT signaling pathway in macrophages (Lee et al., 2018).

\section{Quercetin}

Quercetin is a natural flavonoid compound that is widely found in buckwheat, hawthorn and sea-buckthorn, and has various pharmacological effects such as antioxidant, anti-aging, and antiinflammatory effects (Wang et al., 2021). Muthian et al. treated activated $\mathrm{T}$ cells with quercetin to block IL-12-induced JAK2, Tyk2, STAT3, and STAT4 tyrosine phosphorylation, thereby reducing IL-12-induced $\mathrm{T}$ cell proliferation and Th1 differentiation, to improve experimental autoimmune encephalomyelitis (EAE) (Muthian and Bright, 2004). Senggunprai et al. found that quercetin combined with Epigallocatechin-3-gallate (EGCG) suppressed STAT1 and STAT3 phosphorylation in human holangiocarcinoma (CCA) cells (Senggunprai et al., 2014). In peripheral arterial disease, quercetin inhibits the decline of miR-216a and blocks the JAK2STAT3 and PI3K/Akt pathways, thereby inhibiting HMEC-1 cell survival, migration, and tubulation (Wang et al., 2020).

\section{Flavanones}

\section{Hesperidin and 5,7,3'-Triacetyl Hesperetin}

Hesperidin is mainly derived from the immature citrus fruits of the family Rutin and belongs to one of the dihydroflavones (Zhao et al., 2021). As natural products, hesperidin and TAHP possess extensive pharmacological properties, such as neuroprotective, and anti-inflammatory properties, inhibit the secretion of TNF- $\alpha$ and IL- 6 and reduce the phosphorylation of NF- $\kappa B$; hesperidin in combination with cinnamaldehyde significantly decreased p-JAK2 and p-STAT3 and significantly increased the expression of SOCS3 protein in ulcerative colitis (Elhennawy et al., 2021).

TAHP is a structural derivative of hesperidin. In a rat model of adjuvant arthritis, isomolar TAHP showed more effective antiinflammatory activity than its parent compound hesperidin, and TAHP treatment reduced the expression of STAT3 and JAK2 genes in synovial tissue to varying extents (Ren et al., 2013).

\section{Silibinin}

Silibinin is a flavanone produced from the Milk Thistle, which has anticancer and hepatoprotective effects. When used in combination with traditional chemotherapy, the side effects of chemotherapy drugs, such as nephrotoxicity, gastrointestinal toxicity, and cardiotoxicity, can be reduced, thereby preventing or even reversing chemotherapeutic resistance (Bosch-Barrera et al., 2017). Silibinin also inhibits STAT3 phosphorylation, thereby reducing its transcription activity in ethyl carbamate -induced lung cancer cells in mice (Tyagi et al., 2009). It also inhibits the constitutive activation and apoptosis induction of STAT3 in prostate cancer cells. Compared with silibinin alone, JAK1 inhibitors combined with silibinin also lead to complete reduction of STAT3 phosphorylation at Tyr705, activation of caspase, and apoptosis of prostate cancer cells (Agarwal et al., 2007).

\section{Flavanols}

\section{Epigallocatechin-3-Gallate}

Natural Flavanols include flavan-3-ols, flavan-3,4-diols, and flavan-4-ols (Zakaryan et al., 2017). The derivatives of Flavan3-ols are called catechins. EGCG is a catechin monomer isolated from green tea. STAT3 participates in adipocyte secretomemediated Paracrine regulation of Human MDA-MB-231 (TNBC-derived) cell invasive phenotype, EGCG inhibits p-STAT3 (Gonzalez Suarez et al., 2021). And in IFN$\gamma$-stimulated human oral cancer cells, p-JAK1 and p-JAK2 are inhibited by EGCG, and EGCG inhibits STAT1 translocation to the nucleus (Cheng et al., 2010).

\section{Isoflavones}

\section{Formononetin}

FN is a natural isoflavone found in plants, including Astragalus membranaceus, Clover, Glycyrrhiza glabrifolia, Radix puerariae, and Ryegrass multiflorum. It is considered a typical phytoestrogen and has many biological functions, including neuroprotective, cardiac protection, anticancer, insulin resistance, and immunity regulation (Li et al., 2014). FN reduced JAK1-STAT1 phosphorylation and promoted myoblast differentiation (Soundharrajan et al., 2019). FN promotes apoptosis and inhibits cell proliferation in colorectal cancer by inhibition of cyclin D1 and MMP2/9 expression via p-STAT3 inactivation (Tay et al., 2019). FN also inhibited the phosphorylation and gene expression levels of JAK2 and STAT in HUVECs exposed to high 
glucose concentrations, showing great potential in the treatment of vascular complications of diabetes (Zhou et al., 2019). FT showed a significant anticancer effect in multiple myeloma $(\mathrm{MM})$, which may be mainly through reactive oxygen species (ROS) indirectly down-regulating $\mathrm{p}$-JAK1/2, inhibiting the activation of constitutive p-STAT3, and reducing the binding ability of STAT3/5 to DNA and the translocation of p-STAT3/5 to the nucleus (Kim et al., 2018).

\section{Genistein}

Genistein is a flavonoid that exists in beans and some Chinese herbal medicines, which has a variety of biological effects (Luo et al., 2018). Genistein inhibits GATA-3 and STAT6 and increases the production of T-box transcription factor (T-bet), thereby reducing Th2 type cytokines, increasing Th1 type cytokines, regulating Th1/Th2 response, and alleviating airway inflammation caused by ovalbumin (OVA) (Gao et al., 2012). In Murine J774 macrophages, Genistein inhibits the activation of STAT1, another important transcription factor of inducible nitric oxide synthase (iNOS), In the macrophages of Murine J774 macrophages, Genistein inhibits the activation of STAT1, another important transcription factor of inducible nitric oxide synthase (iNOS), explaining the pharmacological effect of Genistein as an anti-inflammatory compound (Hämäläinen et al., 2007).

\section{Anthocyanidins Malvidin}

Malvidin, a major anthocyanin in blueberries, is involved in the inhibition of inflammation-related mediators in inflammatory diseases and has become a promising anticancer drug because of its powerful antioxidant and antiproliferative effects (Bastin et al., 2021). Treatment with blueberry and malvidin alone or in combination, significantly downregulated the expression of the phosphorylated forms of JAK2 and STAT3. Furthermore, it inhibits nuclear translocation of STAT3, prevents proliferation, induces apoptosis of oral cancer cells in vitro and in vivo (Baba et al., 2017).

\section{Chalcones}

\section{$\alpha$-Bromo-2', 3,4,4'-Tetramethoxychalcone}

Chalcone is a precursor of flavonoids and isoflavones and is found in a variety of fruits, vegetables, and spices, and occurs in nature in many conjugated forms. It has antidiabetic, antitumor, antihypertensive, antiretroviral, anti-inflammatory, antihistamine, antioxidant, anti-malarial, and other pharmacological properties (Mahapatra et al., 2015).

a-Br-TMC inhibited both JAK2 and STAT5 phosphorylation and altered the mobility of STAT5A/B proteins in SDS-PAGE in the IL-3-stimulated $\mathrm{Ba} / \mathrm{F} 3$ cells and its oncogenic derivative $\mathrm{Ba} /$ F3- ${ }^{\star} 6$. The tumor suppressor gene CIS and the oncogene c-Myc are the target genes of STAT5, a-Br-TMC downregulated c-Myc and up-regulated CIS in $\mathrm{Ba} / \mathrm{F} 3-1^{\star} 6$ cells, therefore, $\alpha$-Br-TMC is expected to be used in the treatment and intervention of STAT5 related malignant tumors in the future (Pinz et al., 2014).

\section{$3,4,2^{\prime}, 4^{\prime}$-Tetrahydroxychalcone (Butein)}

Butein is a flavonoid isolated from the bark of the sufa tree, which is believed to have hypotensive, antioxidant, anticancer, antidiabetic, and neuroprotective effects (Padmavathi et al., 2017). In human multiple myeloma (MM) cells, constitutive and IL-6 inducible STAT3 activation are inhibited by inhibiting tyrosine kinases such as JAK1 and JAK2. In addition, Butein downregulates the expression of STAT3 target genes such as Bcl-2 and Mcl-1, leading to increased apoptosis levels (Pandey et al., 2009).

\section{Bavachin}

Bavachin is a phytoestrogen found in the seeds of Psoralea. Bavachin inhibits the activation of STAT3 in MM cells and controls the proliferation of MM cells without cytotoxicity to normal cells (Takeda et al., 2018). In a recent study, IL-6-induced STAT3 activity was inhibited by Bavachin (Lee et al., 2012).

\section{Cardamonin}

Cardamonin is a chalcone found in Zingiberaceae, Asteraceae, Pinaceae, Labiaceae, and other plants and is closely related to antibacterial, anticancer, and other effects. Cardamonin inhibits the activation of ERK1/2 and STAT1-4 and reduces nitric oxide production by targeting the JAK-STAT pathway (Takahashi et al., 2011). Treatment with Cardamonin reduces the secretion of IL$1 \beta$ and TNF- $\alpha$ in patients with recurrent colitis and colitisassociated tumors and inhibits cell viability and the production of inflammatory cytokines in colorectal cancer cells in vitro. In tumor cells, the inhibitory effect of Cardamonin on cell proliferation is closely related to reduced p-STAT (Hou et al., 2019). A study of the treatment of glioblastoma stem cells with Cardamonin found that the activation of STAT3 and downstream regulatory genes of STAT3 were inhibited by Cardamonin. In addition, Cardamonin inhibits the dimerization and nuclear migration of STAT3 in CD133+ GSCs (Wu et al., 2015).

\section{5,7-Dihydroxyflavone}

5,7-Dihydroxyflavone is a natural flavonoid found in propolis, honey, and carnolium (Xie et al., 2011). 5,7-Dihydroxyflavone upregulated the expression of proapoptotic protein Bax, decreased the expression of antiapoptotic proteins Bcl-2, Mcl1 , and IAPS, decreased the phosphorylation levels of Akt and STAT3, and weakened the antiapoptotic signal, thereby promoting human liver cancer cells apoptosis (Zhang et al., 2013).

\section{Biflavones \\ Ginkgetin}

GK is a biological flavonoid compound extracted from Ginkgo biloba leaves and has anticancer, anti-inflammatory, antimicrobial, and neuroprotective activities. GK-treated preadipocytes inhibited the expression of peroxisomal proliferation-activated receptor $\gamma(\operatorname{PPAR} \gamma)$ and CCAAT/ enhancer binding protein a $(\mathrm{C} / \mathrm{EBP} \alpha)$ by inactivating STAT5. The above results indicate that GK can be used as anti-obesity drugs (Cho et al., 2019). GK mediates the dephosphorylation of 
STAT3 in Tyr705 and prevents it from entering the nucleus, thereby inhibiting STAT3-mediated gene expression, such as antiapoptotic Bcl-XL protein, thereby inhibiting the proliferation of prostate cancer DU-145 cells (Jeon et al., 2015). GK dosedependently inhibits STAT3 phosphorylation and significantly reduces Survivin expression in osteosarcoma cells, thereby significantly inhibiting tumor growth (Xiong et al., 2016).

\section{Ohers \\ Casticin}

CST belongs to a group of polymethyl flavonoids obtained from the Vitex, showing a wide range of pharmacological properties, such as anticancer, anti-ulcerative colitis, and antioxidant properties (Song et al., 2017b). CST promotes apoptosis and suppresses p-JAK1 and p-JAK2 and the expression of the phosphorSrc kinase, thereby inhibiting the JAK-STAT pathway in tongue and oral squamous cell carcinomas (Lee et al., 2019).

\section{Kurarinone}

Sophora flavescens, an herbal medicine, contains quinoline alkaloids and flavonoids. Kurarinone has strong inhibitory effect on the immune response and effectively inhibits phosphorylation of STAT1/3 in mouse CD4+T cells (Kim et al., 2013). In addition, in CD4+T cells, the JAK1 and Tyk2dependent phosphorylation of STAT1 and STAT4 was inhibited. Kurarinone also inhibits STAT6 phosphorylation induced by IL4 and STAT5 phosphorylation induced by IL-2 in CD4+T cells.

\section{Stilbenes}

\section{Resveratrol}

Resveratrol is an astragalus compound found in berries, peanuts, and grapes. It is a candidate drug for adjuvant therapy in a variety of inflammatory diseases due to its anti-inflammatory and antioxidant activity (Pinheiro et al., 2019). Resveratrol can downregulate the expression of p-JAK, p-STAT, and inflammatory cytokines, and protects hippocampal neurons from brain ischemia reperfusion injury by regulating the JAKERK-STAT signaling pathway, thereby alleviating cognitive dysfunction (Chang et al., 2018a). Resveratrol can also reduce the expression levels of IL- 6 , TNF- $\alpha$, IFN- $\gamma$, p-JAK1, and p-STAT3 (Tyr705) in the brain tissues of mice with autism, which is important for the treatment of neuroimmune dysfunction (Ahmad et al., 2018). Resveratrol inhibits IFN$\gamma$-induced macrophage STAT1 transcription activity and IFN$\gamma$-induced Tyr701 or Ser727 p-STAT1. It also inhibited IFN$\gamma$-induced activation of JAK2 and extracellular signal-regulated kinases, of which JAK-2 was more sensitive, and blocked the JAKSTAT1 pathway to control the IFN- $\gamma$-activated macrophage inflammatory response (Chung et al., 2011).

\section{Phenolic Acids}

\section{Caffeic Acidand Caffeic Acid Phenethyl Lester}

CA and CAPE are phenolic compounds widely found in wine, tea, and coffee that have hepatoprotective, anti-inflammatory, antiviral, neuroprotective, and immunomodulatory effects (Çakır et al., 2011). In human renal carcinoma cells, CA and CAPE suppress tumor angiogenesis by inhibiting the activity of
STAT3 and the expression of HIF-1 $\alpha$ and Vascular Endothelial Growth Factor (VEGF) (Jung et al., 2007). In stroke-prone spontaneously hypertensive rats (SHRSP), CA inhibits angiotensin II (Ang II)-induced p-JAK2 and p-STAT1, and inhibit the generation of reactive oxygen species, thus partially blocking the JAK-STAT signaling pathway, thereby weakening Ang II-stimulated vascular smooth muscle cell proliferation reaction ( $\mathrm{Li}$ et al., 2005). CAPE can protect the brain from the effects of toxicity of Chromium (VI) by reducing oxidative stress and inflammation in the brain of rats, enhancing antioxidant defense ability, and reversing the upregulation of Chromium (VI) on JAK2, STAT3 and SOCS3 in brain tissues (Mahmoud and Abd El-Twab, 2017).

\section{Lignans}

\section{Anwulignan}

Anwulignan is a monomer compound extracted from lignans in central China (Schroeder et al., 2020), showing a variety of pharmacological properties, including liver protection, antimicrobial, anti-inflammatory, regulation of neuronal survival, and anticancer effects. Anwulignan significantly inhibited the growth of non-small-cell lung carcinoma (NSCLC) cells and increased G1 cell cycle arrest. Anwulignan directly targets JAK1 in vitro to inhibit STAT3 phosphorylation in a dose-dependent manner, attenuate the JAK1-STAT3 pathway, and exert anticancer activity in NSCLC (Xie et al., 2021).

\section{Honokiol}

Honokiol is widely present in Magnolia officinalis and Magnolia grandiflora. It shows antiproliferation, proapoptosis, and regulation of cell cycle activity in the stomach, colon, pancreas, lung, and other solid tumors and leukemia by regulating a variety of carcinogenic targets (Bose et al., 2020). Honokiol inhibits both constitutive and inducible STAT3 activation and reduces the mRNA expression of STAT3 target genes (Bcl-2, cyclin D1, and survival) in myeloid leukemia cells in a concentration-dependent manner (Bi et al., 2015). It also inhibits STAT3 phosphorylation/ activation in an Liver kinase B1 (LKB1)-dependent manner, preventing it from binding to the standard binding sites of Nanog, OC4, and SOX2 promoters (Sengupta et al., 2017). Huang et al. demonstrated that honokiol decreased the levels of phosphorylated JAK2 (p-JAK2) and phosphorylated STAT3 (p-STAT3) in oral cancer cells (Huang et al., 2016).

\section{Others}

\section{Curcumin}

Curcumin, a natural product of plant-derived polyphenols, can be isolated from the rhizome of Curcuma, and is a bioactive component with anti-inflammatory, antitumor, and antioxidative effects. It interferes with multiple signaling pathways that affect tumor proliferation, apoptosis, inflammation, and angiogenesis. In TNBS-induced intestinal inflammation rat models, curcumin can inhibit JAK-STAT pathway by enhancing SOCS-1 expression to achieve antiinflammatory effects (Zhang et al., 2016). SOCS-1 inhibits JAK activity and promotes the proteasomal degradation of JAK. Induction of SOCS-1 led to a sharp downregulation of 
TABLE 2 | Pharmacological effects of polyphenol phytochemicals on the JAK-STAT signaling pathway.

\begin{tabular}{|c|c|c|c|c|}
\hline Phytochemical name & $\begin{array}{c}\text { Source of experimental } \\
\text { evidence }\end{array}$ & Mechanism and effect & Effect & References \\
\hline \multirow[t]{2}{*}{ Apigenin } & $\begin{array}{l}\text { The human colon cancer cell lines } \\
\text { HT29, DLD-1, COLO320, and } \\
\text { HCT116 }\end{array}$ & Inhibited STAT3 phosphorylation. & $\begin{array}{l}\text { Inhibition of STAT3 phosphorylation, } \\
\text { resulting in downregulation of } \\
\text { antiapoptotic proteins } \mathrm{Mcl}-1 \text { and Bcl- } \\
\mathrm{xL} \text { and induces programmed cell } \\
\text { death in colon cancer cells. }\end{array}$ & Maeda et al. (2018) \\
\hline & Adult male BALB/c mice & $\begin{array}{l}\text { Decreased the levels of IL-4, IL-5, IL- } \\
13 \text {, and interferon- } \gamma \text {. Attenuated OVA- } \\
\text { induced alterations in STAT6 and } \\
\text { SOCS1 mRNA expressions. }\end{array}$ & $\begin{array}{l}\text { It plays an anti-allergic role in allergic } \\
\text { rhinitis (AR). }\end{array}$ & Chen et al. (2020) \\
\hline \multirow[t]{3}{*}{ Luteolin } & Human pancreatic cancer cell lines & $\begin{array}{l}\text { Inactivated p-STAT3 and } \\
\text { downregulated STAT3 in a dose- } \\
\text { dependent manner. }\end{array}$ & $\begin{array}{l}\text { Luteolin inhibit pancreatic cancer cell } \\
\text { invasion by inhibiting STAT3 signaling } \\
\text { and secretion of EMT and MMP. }\end{array}$ & Huang et al. (2015) \\
\hline & $\begin{array}{l}\text { Human breast cancer MDA-MB- } \\
231 \text { cells }\end{array}$ & Suppressed STAT3. & $\begin{array}{l}\text { Luteolin enhances paclitaxel-induced } \\
\text { apoptosis through inhibition of the } \\
\text { STAT3 signaling pathway by mediating } \\
\text { Fas expression and activation of } \\
\text { caspases. }\end{array}$ & Yang et al. (2014) \\
\hline & Gastric cancer (GC) cells & $\begin{array}{l}\text { Inhibits STAT3 activation and } \\
\text { dephosphorylated STAT3. }\end{array}$ & $\begin{array}{l}\text { Luteolin selectively kills gastric cancer } \\
\text { cells that are overactivated by STAT3, } \\
\text { and these cells are usually drug- } \\
\text { resistant. }\end{array}$ & Song et al. (2017a) \\
\hline $\begin{array}{l}\text { Kaempferol } 7-O-\beta-D- \\
\text { glucoside (KPG) }\end{array}$ & $\begin{array}{l}\text { The RAW } 264.7 \text { murine } \\
\text { macrophage cell line }\end{array}$ & $\begin{array}{l}\text { Inhibits the phosphorylation of JAK1 } \\
\text { and JAK2. }\end{array}$ & $\begin{array}{l}\text { KPG induces anti-inflammatory activity } \\
\text { by blocking NF- } \mathrm{k}, \mathrm{AP}-1 \text {, and JAK- } \\
\text { STAT signaling pathways in LPS- } \\
\text { treated macrophages. }\end{array}$ & Lee et al. (2018) \\
\hline \multirow[t]{3}{*}{ Quercetin } & SJL/J mice & Blocked IL-12 signaling. & $\begin{array}{l}\text { In vitro treatment of activated T cells } \\
\text { with quercetin blocks IL-12-induced } \\
\text { tyrosine phosphorylation of JAK2, } \\
\text { TYK2, STA T3, and STA T4, resulting } \\
\text { in a decrease in IL-12-induced T cell } \\
\text { proliferation and Th1 differentiation. }\end{array}$ & $\begin{array}{l}\text { Muthian and Bright } \\
\text { (2004) }\end{array}$ \\
\hline & $\begin{array}{l}\text { The human cholangiocarcinoma } \\
\text { (CCA) cell lines }\end{array}$ & $\begin{array}{l}\text { Inhibited IL-6 and IFN- } \gamma \text { and reduced } \\
\text { p-STAT1, and STAT3 proteins in a } \\
\text { dose-dependent manner. }\end{array}$ & $\begin{array}{l}\text { Quercetin and EGCG are beneficial in } \\
\text { inhibiting the JAK-STAT cascade in } \\
\text { CCA cells. }\end{array}$ & $\begin{array}{l}\text { Senggunprai et al. } \\
(2014)\end{array}$ \\
\hline & $\begin{array}{l}\text { Human microvascular endothelial } \\
\text { cells }\end{array}$ & $\begin{array}{l}\text { Inhibition of miR-216a blocked the } \\
\text { JAK2-STAT3 pathway. }\end{array}$ & $\begin{array}{l}\text { Quercetin mainly inhibits survival, } \\
\text { migration, and VEGF expression, and } \\
\text { promotes apoptosis of HMEC-1 cells. }\end{array}$ & Wang et al. (2020) \\
\hline \multirow[t]{2}{*}{$\begin{array}{l}\text { Hesperidin and } 5,7,3^{\prime}- \\
\text { triacetyl hesperetin (TAHP) }\end{array}$} & Adult male Wistar albino rats & $\begin{array}{l}\text { Decreased p-JAK2 and p-STAT3 and } \\
\text { increased SOCS3 protein level. }\end{array}$ & $\begin{array}{l}\text { Cinnamaldehyde and hesperetin } \\
\text { counteract TNBS-induced ulcerative } \\
\text { colitis through modulation of the JAK2- } \\
\text { STAT3-SOCS3 pathway. }\end{array}$ & $\begin{array}{l}\text { Elhennawy et al. } \\
(2021)\end{array}$ \\
\hline & Male Sprague-dawley rats & Decreased STAT3 and JAK2. & $\begin{array}{l}\text { TAHP play a crucial role in the } \\
\text { pathogenesis of AA by regulating the } \\
\text { production of proinflammatory } \\
\text { cytokine IL- } 6 \text { in serum and synovial } \\
\text { tissue and inhibiting the over-activation } \\
\text { of the JAK2-STAT3 signaling pathway. }\end{array}$ & Ren et al. (2013) \\
\hline \multirow[t]{2}{*}{ Silibinin } & $\mathrm{A} / \mathrm{J}$ male mice & $\begin{array}{l}\text { Decreased the phosphorylation level } \\
\text { of STAT3. }\end{array}$ & $\begin{array}{l}\text { By inhibiting the activation of HIF-1 } 1 \alpha \text {, } \\
\text { NF- } \kappa B \text {, and STAT3, lung tumor growth } \\
\text { was inhibited. }\end{array}$ & Tyagi et al. (2009) \\
\hline & $\begin{array}{l}\text { Human prostate carcinoma DU145 } \\
\text { cell }\end{array}$ & Inhibited constitutively active STAT3. & $\begin{array}{l}\text { It effectively inhibited the constitutive } \\
\text { activation and apoptosis induction of } \\
\text { STAT3 in DU145 cells }\end{array}$ & $\begin{array}{l}\text { Agarwal et al. } \\
(2007)\end{array}$ \\
\hline
\end{tabular}

(Continued on following page) 
TABLE 2 | (Continued) Pharmacological effects of polyphenol phytochemicals on the JAK-STAT signaling pathway.

\begin{tabular}{|c|c|c|c|}
\hline Phytochemical name & $\begin{array}{c}\text { Source of experimental } \\
\text { evidence }\end{array}$ & Mechanism and effect & Effect \\
\hline \multirow[t]{2}{*}{$\begin{array}{l}\text { Epigallocatechin-3-gallate } \\
\text { (EGCG) }\end{array}$} & $\begin{array}{l}\text { Human MDA-MB-231 (TNBC- } \\
\text { derived) cell }\end{array}$ & Inhibited p-STAT3. & $\begin{array}{l}\text { EGCG prevented a STAT3-mediated } \\
\text { paracrine oncogenic control of triple- } \\
\text { negative breast cancer cell invasive } \\
\text { phenotype }\end{array}$ \\
\hline & Human oral cancer cells & $\begin{array}{l}\text { Inhibited p-JAK1/2 and suppressed } \\
\text { STAT1 translocation to the nucleus. }\end{array}$ & $\begin{array}{l}\text { Indoleamine 2,3-dioxygenase, an } \\
\text { immunomodulatory protein, is } \\
\text { suppressed by EGCG via blocking of } \\
\text { gamma-interferon-induced JAK-PKC- } \\
\text { delta-STAT1 signaling in human oral } \\
\text { cancer cells. }\end{array}$ \\
\hline
\end{tabular}

\begin{tabular}{lll}
\hline Formononetin $(\mathrm{FN})$ & $\begin{array}{ll}\text { The C2C12 mouse myogenic } \\
\text { progenitor cells }\end{array}$ & $\begin{array}{l}\text { Decreased JAK1-STAT1 } \\
\text { phosphorylation level. }\end{array}$
\end{tabular}

\section{FN treatment activates myogenic}

Soundharrajan

differentiation by increasing p38MAPK et al. (2019) and decreasing JAK1-STAT1 phosphorylation levels.

The human colon carcinoma cell Reduced p-STAT3 protein level. lines SW1116 and HCT116

FN suppresses cell proliferation and invasion by inhibition of cyclin D1 and MMP2/9 expression via p-STAT3 inactivation in colon carcinoma cells.

HuVecs

Human MM cell line U266 and human myeloma cell line RPMI 8226, athymic nu/nu female mice

$\begin{array}{lll}\text { Genistein } & \text { Balb/c mice } \quad \text { Inhibited STAT6. }\end{array}$

Murine $\mathrm{J} 774$ macrophages Inhibited activation of STAT1.

THP1 human monocytic cells

$\mathrm{Ba} / \mathrm{F} 3$ and $\mathrm{Ba} / \mathrm{F} 3-1^{\star} 6$ cells

a-Bromo-2',3,4,4'tetramethoxychalcone (a-Br-TMC)

$3,4,2^{\prime}, 4^{\prime}-$ tetrahydroxychalcone (Butein) Human multiple myeloma (MM) U266

Inhibited the phosphorylation and the mRNA expression levels of JAK2 and STAT.

Inhibited the cascade of STAT3 and STAT5 signals.

FN may be a new potential therapeutic compound for the treatment of vascular complications of diabetes. FN shows anticancer effect in MM.

\section{Gonzalez Suarez} et al. (2021)

Cheng et al. (2010)

Wang et al. (2018)

Zhou et al. (2019)

Kim et al. (2018)

Modulates the Th1/Th2 reaction by

Gao et al. (2012) inhibiting GATA-3 and STAT6 production while increasing $\mathrm{T}$-bet production.

Genistein inhibited LPS-induced STAT-1 expression.

Hämäläinen et al. (2007) $\begin{array}{ll}\text { Suppressed STAT3 phosphorylation } & \text { Malvidin inhibits the JAK-STAT } \\ \text { and nuclear translocation. } & \text { pathway and blocks inflammation. }\end{array}$

Baba et al. (2017) A-BR-TMC can be used in the Pinz et al. (2014) treatment of STAT5-related malignancies.

a-Br-TMC inhibited JAK2 and STAT5 phosphorylation.

Inhibition of tumor cell proliferation and reversal of chemotherapy resistance in multiple myeloma cells by blocking STAT3 activation.

Inhibited the activation of JAK1/2.

Bavachin
IM9 cells, RPMI 8226 cells, and

Inhibited activation of STAT3. RPMI 1788 cells. Male BALB/C mice Hep3B cells Inhibited STAT3 promoter activity.

Bavachin induces apoptosis by inhibiting the activation of NF-кB and STAT3 in multiple myeloma cell lines. Bavachin treats inflammatory diseases by inhibiting the activation and phosphorylation of STAT3 induced by IL-6.

\begin{tabular}{|c|c|c|}
\hline \multirow[t]{3}{*}{ Cardamonin } & Female ICR mice & Inhibited the activation of STAT1 - 4 . \\
\hline & $\begin{array}{l}\text { The human colon cancer cell line } \\
\text { HT-29 and SW-460, and C57BL/6 } \\
\text { mice }\end{array}$ & $\begin{array}{l}\text { Reduced the secretion of } \mathrm{IL}-1 \beta \text { and } \\
\text { TNF- } \alpha \text {, and inhibited the } \\
\text { phosphorylation of STAT. }\end{array}$ \\
\hline & CD133+GSCs & $\begin{array}{l}\text { Inhibited the activation of STAT3 and } \\
\text { the expression of downstream STAT3 } \\
\text { genes, and prevented the migration of } \\
\text { STAT3 to the nucleus and } \\
\text { dimerization. }\end{array}$ \\
\hline
\end{tabular}

Targets the production of IFN- and thereby suppresses the STAT pathway to mitigate inflammation. In the treatment of recurrent colitis and Hou et al. (2019) colitis-related tumors. ABU can inhibit cell viability and inflammatory cytokines of colorectal cancer cells in vitro.

Cardamonin is a novel inhibitor of STAT3 and has the potential to be developed as a new anticancer agent targeting GSCs.
Takeda et al. (2018)

Lee et al. (2012)

Pandey et al. (2009) Takahashi et al. (2011)

Wu et al. (2015) 
TABLE 2 | (Continued) Pharmacological effects of polyphenol phytochemicals on the JAK-STAT signaling pathway.

\begin{tabular}{|c|c|c|c|c|}
\hline Phytochemical name & $\begin{array}{c}\text { Source of experimental } \\
\text { evidence }\end{array}$ & Mechanism and effect & Effect & References \\
\hline 5,7-Dihydroxyflavone & $\begin{array}{l}\text { Human hepatocellular carcinoma } \\
\text { (HepG2) and BALB/c female nude } \\
\text { mice }\end{array}$ & $\begin{array}{l}\text { Decreased the phosphorylation of } \\
\text { STAT3. }\end{array}$ & $\begin{array}{l}\text { The phosphorylation level of STAT3 } \\
\text { was decreased, the antiapoptotic } \\
\text { signal was weakened, and the growth } \\
\text { of xenograft of HepG } 2 \text { tumor was } \\
\text { significantly inhibited. }\end{array}$ & Zhang et al. (2013) \\
\hline \multirow[t]{3}{*}{ Ginkgetin (GK) } & C57BL/6 male mice and 3T3-L1 & Inhibited STAT5 activity. & $\begin{array}{l}\text { The inhibition of PPAR } \gamma \text { and C/EBPa } \\
\text { expression by Ginkgo biloba } \\
\text { flavonoids was due to STAT5 } \\
\text { inactivation at the initial stage of } \\
\text { adipogenesis. }\end{array}$ & Cho et al. (2019) \\
\hline & $\begin{array}{l}\text { Human cancer cell lines HCT-116, } \\
\text { DU-145, LNCap and PC-3 }\end{array}$ & $\begin{array}{l}\text { Mediated dephosphorylation of } \\
\text { STAT3. }\end{array}$ & $\begin{array}{l}\text { Ginkgetin blocks its entry into the } \\
\text { nucleus, which in turn inhibits STAT3- } \\
\text { mediated gene expression, thus } \\
\text { inhibits the proliferation of DU-145 } \\
\text { prostate cancer cells. }\end{array}$ & Jeon et al. (2015) \\
\hline & Giant cell tumor samples & Inhibited STAT3 phosphorylation. & $\begin{array}{l}\text { Ginkgetin significantly reduced survivin } \\
\text { expression, which significantly } \\
\text { inhibited tumor growth. }\end{array}$ & Xiong et al. (2016) \\
\hline Casticin (CST) & 786-O, HEL 299 & $\begin{array}{l}\text { Inhibited } \mathrm{p} \text {-JAK1/2 and the } \\
\text { expression of the phosphorSrc kinase }\end{array}$ & $\begin{array}{l}\text { Casticin inhibits the JAK-STAT } \\
\text { pathway in tongue squamous cell } \\
\text { carcinoma, hypertriploid renal cell } \\
\text { carcinoma, and oral squamous cell } \\
\text { carcinoma. }\end{array}$ & Lee et al. (2019) \\
\hline Kurarinone & $\begin{array}{l}\text { The immortalized human } \\
\text { keratinocyte cell line HaCaT and } \\
\text { C57BL/6 mice or OT-II transgenic } \\
\text { mice }\end{array}$ & $\begin{array}{l}\text { Inhibitory phosphorylation of STAT1, } \\
\text { STAT3, STAT5, and STAT6. }\end{array}$ & $\begin{array}{l}\text { Suppresses JAK/STAT-dependent } \\
\text { CD4+T-cell differentiation and } \\
\text { improves chronic inflammatory skin } \\
\text { diseases by inhibiting pro- } \\
\text { inflammatory mediators, the JAK- } \\
\text { STAT pathway, and the general } \\
\text { immune response. }\end{array}$ & Kim et al. (2013) \\
\hline \multirow[t]{3}{*}{ Resveratrol } & Sprague-dawley rats & $\begin{array}{l}\text { Downregulated the p-JAK, p-STAT, } \\
\text { and inflammatory cytokines. }\end{array}$ & $\begin{array}{l}\text { Resveratrol protects hippocampal } \\
\text { neurons from cerebral ischemia/ } \\
\text { reperfusion injury and alleviates } \\
\text { cognitive dysfunction by regulating } \\
\text { JAK-ERK-STAT signaling pathway. }\end{array}$ & $\begin{array}{l}\text { Chang et al. } \\
(2018 \mathrm{a})\end{array}$ \\
\hline & $\begin{array}{l}\text { BTBR T+ Itpr3tf/J (BTBR) and } \\
\text { C57BL/6 male mice }\end{array}$ & $\begin{array}{l}\text { Decreased the expression levels of IL- } \\
6 \text {, TNF- } \alpha \text {, IFN- } \gamma \text {, p-STAT1, and } \\
\text { p-STAT3 (Tyr705). }\end{array}$ & $\begin{array}{l}\text { Resveratrol can also inhibit JAK1- } \\
\text { STAT3 in the brain tissue of autistic } \\
\text { mice and treat neuroimmune } \\
\text { dysfunction. }\end{array}$ & Ahmad et al. (2018) \\
\hline & RAW 264.7 macrophages & $\begin{array}{l}\text { Inhibited the transcriptional activity } \\
\text { and phosphorylation of STAT1. }\end{array}$ & $\begin{array}{l}\text { Resveratrol controls the inflammatory } \\
\text { response of interferon- } \gamma \text {-activated } \\
\text { macrophages. }\end{array}$ & Chung et al. (2011) \\
\hline \multirow[t]{3}{*}{$\begin{array}{l}\text { Caffeic acid (CA) and Caffeic } \\
\text { acid phenethylester (CAPE) }\end{array}$} & $\begin{array}{l}\text { The Caki-I human renal carcinoma } \\
\text { and COS7 monkey kidney cell lines }\end{array}$ & $\begin{array}{l}\text { Suppressed p-STAT3 and STAT3- } \\
\text { inducible VEGF gene expression. }\end{array}$ & $\begin{array}{l}\text { CA and CAPE suppress tumor } \\
\text { angiogenesis by inhibiting the activity } \\
\text { of STAT3 and the expression of HIF-1a } \\
\text { and VEGF }\end{array}$ & Jung et al. (2007) \\
\hline & SHRSP and WKY rats & $\begin{array}{l}\text { Abolished the tyrosine } \\
\text { phosphorylation of JAK2 and STAT1. }\end{array}$ & $\begin{array}{l}\text { CA attenuated the proliferative } \\
\text { response of SHRSP and WKY rat } \\
\text { vascular smooth muscle cells to Ang } \\
\text { stimulation by partially blocking the } \\
\text { JAK-STAT signaling cascade and the } \\
\text { RAS/RAF-1/ERK1/2 cascade. }\end{array}$ & Li et al. (2005) \\
\hline & Male wistar rats (Rattus norvegicus) & $\begin{array}{l}\text { Downregulated cerebral JAK2 } \\
\text { expression, STAT3 phosphorylation, } \\
\text { and SOCS3 protein expression. }\end{array}$ & $\begin{array}{l}\text { CAPE can reduce oxidative stress and } \\
\text { inflammation in the brain of rats, } \\
\text { enhance antioxidant defense ability, } \\
\text { and reverse the upregulation of } \\
\text { Chromium (VI) on JAK2, STAT3 and } \\
\text { SOCS3 in brain tissues. }\end{array}$ & $\begin{array}{l}\text { Mahmoud and } \\
\text { Abd El-Twab } \\
\text { (2017) }\end{array}$ \\
\hline
\end{tabular}


TABLE 2 | (Continued) Pharmacological effects of polyphenol phytochemicals on the JAK-STAT signaling pathway.

\begin{tabular}{|c|c|c|c|c|}
\hline Phytochemical name & $\begin{array}{l}\text { Source of experimental } \\
\text { evidence }\end{array}$ & Mechanism and effect & Effect & References \\
\hline Anwulignan & $\begin{array}{l}\text { Human NSCLC cell lines A549, } \\
\text { H1299, H1650, and H1975. }\end{array}$ & $\begin{array}{l}\text { Inhibited the phosphorylation of } \\
\text { STAT3 by directly targeting JAK1. }\end{array}$ & $\begin{array}{l}\text { Anwulignan is a novel JAK1 inhibitor } \\
\text { that may have therapeutic implications } \\
\text { for NSCLC management. }\end{array}$ & Xie et al. (2021) \\
\hline \multirow[t]{3}{*}{ Honokiol } & $\begin{array}{l}\text { Human oral squamous cell } \\
\text { carcinoma (OSCC) cell line }\end{array}$ & $\begin{array}{l}\text { Reduced the levels of } \mathrm{p}-\mathrm{JAK} 2 \text { and } \\
\text { p-STAT3. }\end{array}$ & $\begin{array}{l}\text { Honokiol suppressed the sphere } \\
\text { formation and xenograft growth of oral } \\
\text { CSC-like associated cells. }\end{array}$ & Huang et al. (2016) \\
\hline & Breast cancer cells & $\begin{array}{l}\text { Induced increase in tumor suppressor } \\
\text { LKB1 led to dephosphorylation and } \\
\text { inactivation of STAT3. }\end{array}$ & $\begin{array}{l}\text { HNK inhibited breast tumorigenesis in } \\
\text { mice in an LKB1-dependent manner. }\end{array}$ & $\begin{array}{l}\text { Sengupta et al. } \\
\text { (2017) }\end{array}$ \\
\hline & $\begin{array}{l}\text { Human leukemia cell lines (HEL and } \\
\text { THP1) }\end{array}$ & $\begin{array}{l}\text { Inhibited STAT3 transcription activity, } \\
\text { reduced nuclear translocation of } \\
\text { STAT3, and decreased STAT3 target } \\
\text { gene expression. }\end{array}$ & $\begin{array}{l}\text { HNK plays an anticancer role in acute } \\
\text { myeloid leukemia by inhibiting STAT3 } \\
\text { signaling. }\end{array}$ & Bi et al. (2015) \\
\hline \multirow[t]{2}{*}{ Curcumin } & Sprague dawley male rats & Enhanced SOCS-1 expression. & $\begin{array}{l}\text { The anti-inflammatory effect of } \\
\text { curcumin is realized by enhancing } \\
\text { SOCS-1 expression and inhibiting the } \\
\text { JAK-STAT pathway. }\end{array}$ & Zhang et al. (2016) \\
\hline & Human OS cell line (MG-63) & Inhibited p-JAK2 and p-STAT3. & $\begin{array}{l}\text { Curcumin inhibits the JAK-STAT } \\
\text { pathway to induce G0/G1 phase } \\
\text { arrest and apoptosis, and inhibits the } \\
\text { proliferation and migration of } \\
\text { osteosarcoma cells. }\end{array}$ & Sun et al. (2019b) \\
\hline Wedelolactone & $\begin{array}{l}\text { HepG2, WiDr, A431, and A549 } \\
\text { cells }\end{array}$ & $\begin{array}{l}\text { Specifically inhibited TCPTP, the } \\
\text { major phosphatase of STAT1, and } \\
\text { prolonged IFN- } \gamma \text {-induced STAT1 } \\
\text { phosphorylation. }\end{array}$ & $\begin{array}{l}\text { Wedelolactone enhanced the } \\
\text { antitumor effect of IFN- } \gamma \text { by inhibiting } \\
\text { TCPTP-mediated STAT1 } \\
\text { dephosphorylation. }\end{array}$ & Chen et al. (2013) \\
\hline
\end{tabular}

JAK2-STAT signaling and mRNA levels of target genes directly regulated by JAK2 (Ungureanu et al., 2002), and competition with STATs for binding to cytokine receptors, thus effectively inhibiting the JAK-STAT pathway and inhibiting proinflammatory responses. It can also dose-dependently inhibit the p-JAK2-p-STAT3 pathway to induce G0/G1 phase arrest and apoptosis, and inhibit the proliferation and migration of osteosarcoma cells (Sun et al., 2019b).

\section{Wedelolactone}

Wedelolactone is a coumarin found in Wedelia calendulacea and Eclipta prostrata that has anti-proteolytic, anti-inflammatory, anti-hepatotoxic, and anticancer properties owing to its multimolecular targets (Svrlanska et al., 2020). Wedelolactone significantly prolonged the duration of STAT1 tyrosine phosphorylation and prolonged the IFN- $\gamma$-induced STAT1 phosphorylation by inhibiting the $\mathrm{T}$-cell protein tyrosine phosphatase (TCPTP)-dependent dephosphorylation of STAT1 and synergized with IFN- $\gamma$ in inducing cell death among certain STAT1 expressing tumor cells (Chen et al., 2013) (Table 2).

\section{CONCLUSION AND FUTURE PERSPECTIVES}

Abnormal mutations in the JAK-STAT signaling pathway are closely related to the occurrence and development of malignant tumors, inflammation and autoimmune diseases. In this review, we wrote more than 20 kinds of polyphenolic phytochemicals and found that the mechanism of action of these polyphenol phytochemicals on the JAK-STAT signaling pathway is not completely the same. Some compounds can directly act on the JAK-STAT pathway, such as Luteolin, KPG, Butein, Casticin, Genistein, Silibinin, Kurarinone, 5,7Dihydroxyflavone, Ginkgetin, Capillarisin, Bavachin, $\mathbf{a - B r}-$ TMC, Formononetin, Anwulignan, Capsaicin, Malvidin, these compounds can directly affect the JAK-STAT signaling pathway in three ways: 1) inhibit the phosphorylation of JAK and (or) STAT 2) inhibit the activation and expression of JAK and (or) STAT 3) interfere with the movement and nuclear translocation of STAT, and affect the regulation of STAT target genes. Other compounds have different mechanisms of action in different diseases, such as Apigenin, Quercetin, Hesperidin, TAHP, Cardamonin, Resveratrol, Caffeic acid phenethylester, Honokiol, and Curcumin. They can not only directly act on the JAK-STAT signal pathway through the above methods, but also indirectly regulate the JAK-STAT pathway through the following methods: 1) inhibit the secretion of interleukins, interferons, tumor necrosis factor and other cytokines 2) interfere with the process by which the JAK-STAT pathway is activated by cytokines 3) indirectly regulate the JAK-STAT signaling pathway by regulating endogenous inhibitors in the pathway, such as SOCS. 
According to the chemical structure, we divided the 26 phytochemicals in this article into flavonoids, phenolic acids, stilbenes, lignans and some compounds with complex parent nuclei, and classified the flavonoids in more detail. We found that some compounds have similar pharmacological effects, which may be related to their chemical structure. Flavones are compounds with 2-phenyl-chromone as parent nuclei, including Apigenin and Luteolin. We found that flavones represented by Apigenin and Luteolin can directly inhibit the phosphorylation of STAT3 in breast cancer cells, which may be related to the structure of flavones. Flavonols are derivatives of 2phenylchrominones-3-alcohols, including kaempferol, quercetin. Both KPG and Quercetin inhibit p-JAK2 and p-STAT3 in inflammatory diseases. Flavanones have 2-phenyl-2,3Chromanone basic nucleus, Flavanones include Hesperidin, Liquiritin. Hesperidin and Silibinin can interfere in different diseases by affecting STAT3 expression and phosphorylation. Flavanonols have 2-phenyl-2,3-Chromanone-3-alcohol nucleus. The mother nucleus structure of Anthocyanidins is 2phenylbenzopyrylium salts or flavylium salts and Malvidin is one of the more common anthocyanins. Malvidin significantly down-regulates the expression of JAK2 and STAT3 phosphorylated forms, and inhibits the STAT3 nuclear translocation. The skeleton of Chalcones is formed by the opening of the $\mathrm{C}$ ring of flavanonols. The numbering of the carbon atoms of the nucleus is different from other types of flavonoids. The carbon of the A ring is $1^{\prime}-6^{\prime}$, and the carbon of the $\mathrm{B}$ ring is $1-6$. Among the four Chalcones, Butein, Bavachin and Cardamonin can play a role in multiple myeloma and other diseases by inhibiting the activation and expression of STAT3. Lignans are natural products formed from two structures with phenylpropane skeletons connected by the $\beta, \beta^{\prime}$, or $8,8^{\prime}$-carbons. Anwulignan and Honokiol can down-regulate p-STAT3 in various cancers (NSCLC, breast cancer, oral cancer, and myeloid leukemia). Phenolic acid compounds refer to aromatic carboxylic acid compounds substituted with multiple phenolic hydroxyl groups on a benzene ring. They are plant secondary metabolites. Phenolic acids can be divided into two categories according to their carbon skeleton structure: Hydroxybenzoic acid and hydroxycinnamic acids. There are two other types that are formed by condensation: chlorogenic acid is a combination of caffeic acid and quinic acid through an ester bond, and salvianolic acid is a polymer of simple phenolic acid. Among the members of the STATs family of proteins, STAT3 plays an important role in cell proliferation, inflammation, tumorigenesis and other vital activities and is most frequently activated and mutated in the occurrence and development of tumors. It was found that most polyphenol phytochemicals have an effect on STAT3.

There are currently many studies on inhibitors of JAK kinase, such as tofacitinib and ruxolitinib, which have been approved by the United States Food and Drug Administration (FDA), which have a good inhibitory effect on some lymphoma tumors. However, at higher doses, they exhibit "pan-JAK" inhibitory effects, resulting in off-target effects, causing infection, malignant tumors, venous thromboembolism (VTE), dyslipidemia, gastrointestinal perforation and other adverse reactions (Reddy and Cohen, 2020). For example, on February
25,2019 , the first JAK inhibitor tofacitinib on the market found that high-dose tofacitinib in patients with rheumatoid arthritis could lead to the risk of pulmonary thrombosis and death. On August 28, 2019, the FDA also required the drug label to add a black box warning of "thrombosis and death risk" (Kaufmann et al., 2018). At this point, polyphenolic compounds that also target JAK such as KPG, EGCG, Butein, and Casticin have been found to have less adverse effects and toxicity currently. STATs family proteins are highly active in malignant tumors and other diseases, but the development of STATs inhibitors has always been a major problem due to their bioavailability and the difficulty of improving the selectivity in vivo. Therefore, most drugs targeting STATs are still in the preclinical stage. Apigenin, Luteolin, Silibinin and other compounds can specifically inhibit STAT. Honokiol inhibits both constitutive and inducible STAT3 activation and reduces the mRNA expression of STAT3 target genes (Bcl-2, cyclin D1, and survival) in myeloid leukemia cells in a concentration-dependent manner. Formononetin (FN) can inhibit both STAT3 and STAT5 in human MM cells. These compounds can make up for the current lack of STAT inhibitors.

But compared with polyphenolic phytochemicals, JAK inhibitors also have their advantages. In the treatment of RA, JAK inhibitors have a unique mechanism of action, which has the advantages of rapid onset, long-lasting efficacy, and no risk of secondary failure, which are different from biological agents (Buhl et al., 2021). For example, in a long-term clinical trial (NCT00413699), tofacitinib showed its stable efficacy for up to 9.5 years. Polyphenols contain a large amount of phenolic hydroxyl groups, many of them are poorly water-soluble due to the spatial structure, which may lead to huge differences in the results of in vivo and in vitro models. Part of the reason is that the metabolism of polyphenols in the body is very complicated. For example, many insoluble components can be metabolized by gut microbiota. This is especially obvious in phenolic acid compounds, due to the substitution of more phenolic hydroxyl groups in phenolic acid compounds' structure, the structure is not stable, and it is easy to denature under the action of acidic, alkaline environment, unsuitable temperature and enzymes. There is abundant experimental data on the intervention of Flavonoids and less data on the effect of other types of polyphenol phytochemicals on the pathway. The limitations of many phytochemicals include low water solubility, poor absorption and bioavailability, which may limit their effects in clinical treatments. Unlike drugs that can be administered in specific doses and at specific times in a particular situation, Phytochemicals are often ingested at random intervals and concentrations in people's diets. Achieving adequate phytochemical concentrations and bioavailability, by ingesting foods at concentrations similar to those of the drug in the study environment, is a challenge (Bose et al., 2020). These impressive findings confirm the importance and necessity of phytochemicals in clinical trials.

More than 20 compounds have different pharmacological effects in the JAK-STAT signaling pathway. However, we believe that curcumin may be the most promising potential treatment in the future. First of all, curcumin has been proven effective in animal and cell experimental models of a variety of 
diseases. In addition to the two mechanisms listed above, it is also effective in intestinal inflammation (Zhang et al., 2016), Papillary Thyroid Cancer (Khan et al., 2020), triple-negative breast cancer (Bonaccorsi et al., 2019), Small Cell Lung Cancer (Yang et al., 2012) and other diseases have been proven to have a therapeutic effect by acting on the JAK-STAT pathway. For example, in the Papillary Thyroid Cancer cell line, by inhibiting JAK/STAT3 activity and inhibiting anti-apoptotic genes and inducing proapoptotic genes, curcumin and cisplatin synergistically enhance cytotoxicity, and also through down-regulation of matrix metalloproteinases and inhibition of colony formation to inhibit the migration of PTC cells. In addition, curcumin can not only directly act on the JAK-STAT pathway, but also indirectly play a role by inhibiting the secretion of cytokines and enhancing the negative regulatory factors in the cells.

Owing to the nature of the JAK-STAT pathway and its potential cross-epitope with multiple alternative pathways, the long-term efficacy of adaptive targeted therapies based on monotherapy is limited. At the same time, phytochemicals have shown good potency in the treatment of cancer, diabetes, Alzheimer's disease, and other diseases (Batra et al., 2019). Polyphenols can inhibit abnormal activation by acting on multiple steps in the JAK-STAT pathway. For example, Curcumin inhibits both the constitutive and IL-6-induced STAT3 phosphorylation and IFN-induced STAT1 phosphorylation. The multi-activity and multi-targeting of

\section{REFERENCES}

Aavikko, M., Kaasinen, E., Nieminen, J. K., Byun, M., Donner, I., Mancuso, R., et al. (2015). Whole-Genome Sequencing Identifies STAT4 as a Putative Susceptibility Gene in Classic Kaposi Sarcoma. J. Infect. Dis. 211 (11), 1842-1851. doi:10.1093/infdis/jiu667

Agarwal, C., Tyagi, A., Kaur, M., and Agarwal, R. (2007). Silibinin Inhibits Constitutive Activation of Stat3, and Causes Caspase Activation and Apoptotic Death of Human Prostate Carcinoma DU145 Cells. Carcinogenesis 28 (7), 1463-1470. doi:10.1093/carcin/bgm042

Agrawal, S., Gollapudi, S., Su, H., and Gupta, S. (2011). Leptin Activates Human B Cells to Secrete TNF- $\alpha$, IL-6, and IL-10 via JAK2/STAT3 and p38MAPK/ ERK1/2 Signaling Pathway. J. Clin. Immunol. 31 (3), 472-478. doi:10.1007/ s10875-010-9507-1

Ahmad, S. F., Ansari, M. A., Nadeem, A., Bakheet, S. A., Alzahrani, M. Z., Alshammari, M. A., et al. (2018). Resveratrol Attenuates Pro-Inflammatory Cytokines and Activation of JAK1-STAT3 in BTBR T+ Itpr3tf/J Autistic Mice. Eur. J. Pharmacol. 829, 70-78. doi:10.1016/j.ejphar.2018.04.008

Aota, K., Yamanoi, T., Kani, K., Ono, S., Momota, Y., and Azuma, M. (2021). Inhibition of JAK-STAT Signaling by Baricitinib Reduces Interferon- $\gamma$-Induced CXCL10 Production in Human Salivary Gland Ductal Cells. Inflammation 44 (1), 206-216. doi:10.1007/s10753-020-01322-w

Ashrafizadeh, M., Rafiei, H., Mohammadinejad, R., Afshar, E. G., Farkhondeh, T., and Samarghandian, S. (2020). Potential Therapeutic Effects of Curcumin Mediated by JAK/STAT Signaling Pathway: A Review. Phytother Res. 34 (8), 1745-1760. doi:10.1002/ptr.6642

Baba, A. B., Nivetha, R., Chattopadhyay, I., and Nagini, S. (2017). Blueberry and Malvidin Inhibit Cell Cycle Progression and Induce Mitochondrial-Mediated Apoptosis by Abrogating the JAK/STAT-3 Signalling Pathway. Food Chem. Toxicol. 109, 534-543. doi:10.1016/j.fct.2017.09.054

Barilà, G., Teramo, A., Calabretto, G., Vicenzetto, C., Gasparini, V. R., Pavan, L., et al. (2020). Stat3 Mutations Impact on Overall Survival in Large Granular Lymphocyte Leukemia: A Single-Center Experience of 205 Patients. Leukemia 34 (4), 1116-1124. doi:10.1038/s41375-019-0644-0 phytochemicals and their mitigation of the toxic and side effects of chemotherapeutic agents have shown better clinical effects. For example, Compared with silibinin alone, JAK1 inhibitors combined with silibinin also lead to complete reduction of STAT3 phosphorylation at Tyr705, activation of caspase, and apoptosis of prostate cancer cells. Therefore, it may be worthwhile to further explore the use of JAK/STAT inhibitors in combination with polyphenolic phytochemicals.

\section{AUTHOR CONTRIBUTIONS}

The research project was designed by QY, LW, WZ, and CS; QY, LW, HY, and DC contributed to the collection of literature and relevant information; QY and LW wrote the manuscript and checked the Tables and Figures as well as grammar of manuscript with help from WZ and CS; HY and DC drew structures and revised the manuscript. All authors contributed to the article and approved thesubmitted version.

\section{FUNDING}

This work was supported by the National Natural Science Foundation of China (grant number 81973677, grant number 81973798).

Bastin, A., Sadeghi, A., Nematollahi, M. H., Abolhassani, M., Mohammadi, A., and Akbari, H. (2021). The Effects of Malvidin on Oxidative Stress Parameters and Inflammatory Cytokines in LPS-Induced Human THP-1 Cells. J. Cel Physiol. 236 (4), 2790-2799. doi:10.1002/jcp.30049

Batra, H., Pawar, S., and Bahl, D. (2019). Curcumin in Combination with AntiCancer Drugs: A Nanomedicine Review. Pharmacol. Res. 139, 91-105. doi:10.1016/j.phrs.2018.11.005

Bi, L., Yu, Z., Wu, J., Yu, K., Hong, G., Lu, Z., et al. (2015). Honokiol Inhibits Constitutive and Inducible STAT3 Signaling via PU.1-Induced SHP1 Expression in Acute Myeloid Leukemia Cells. Tohoku J. Exp. Med. 237 (3), 163-172. doi:10.1620/tjem.237.163

Bodmer, D., Kern, P., Bächinger, D., Monge Naldi, A., and Levano Huaman, S. (2020). STAT1 Deficiency Predisposes to Spontaneous Otitis media. PloS one 15 (9), e0239952. doi:10.1371/journal.pone.0239952

Bonaccorsi, P. M., Labbozzetta, M., Barattucci, A., Salerno, T. M. G., Poma, P., and Notarbartolo, M. (2019). Synthesis of Curcumin Derivatives and Analysis of Their Antitumor Effects in Triple Negative Breast Cancer (TNBC) Cell Lines. Pharmaceuticals (Basel) 12 (4), 161. doi:10.3390/ph12040161

Bosch-Barrera, J., Queralt, B., and Menendez, J. A. (2017). Targeting STAT3 with Silibinin to Improve Cancer Therapeutics. Cancer Treat. Rev. 58, 61-69. doi:10.1016/j.ctrv.2017.06.003

Bose, S., Banerjee, S., Mondal, A., Chakraborty, U., Pumarol, J., Croley, C. R., et al. (2020). Targeting the JAK/STAT Signaling Pathway Using Phytocompounds for Cancer Prevention and Therapy. Cells 9 (6), 1451. doi: $10.3390 /$ cells 9061451

Buhl, T., Rosmarin, D., Serra-Baldrich, E., Fernandez-Peñas, P., Igarashi, A., Konstantinou, M. P., et al. (2021). Itch and Sleep Improvements with Baricitinib in Patients with Atopic Dermatitis: A Post Hoc Analysis of 3 Phase 3 Studies. Dermatol. Ther. (Heidelb) 11 (3), 971-982. doi:10.1007/ s13555-021-00534-8

Byers, L. A., Sen, B., Saigal, B., Diao, L., Wang, J., Nanjundan, M., et al. (2009). Reciprocal Regulation of C-Src and STAT3 in Non-small Cell Lung Cancer. Clin. Cancer Res. 15 (22), 6852-6861. doi:10.1158/1078-0432.Ccr-09-0767

Çakır, T., Özkan, E., Dulundu, E., Topaloğlu, Ü., Şehirli, A. Ö., Ercan, F., et al. (2011). Caffeic Acid Phenethyl Ester (CAPE) Prevents Methotrexate-Induced 
Hepatorenal Oxidative Injury in Rats. J. Pharm. Pharmacol. 63 (12), 1566-1571. doi:10.1111/j.2042-7158.2011.01359.x

Casanova, J. L., Holland, S. M., and Notarangelo, L. D. (2012). Inborn Errors of Human JAKs and STATs. Immunity 36 (4), 515-528. doi:10.1016/ j.immuni.2012.03.016

Chang, C., Zhao, Y., Song, G., and She, K. (2018a). Resveratrol Protects Hippocampal Neurons against Cerebral Ischemia-Reperfusion Injury via Modulating JAK/ERK/STAT Signaling Pathway in Rats. J. Neuroimmunol 315, 9-14. doi:10.1016/j.jneuroim.2017.11.015

Chang, Z., Wang, Y., Zhou, X., and Long, J. E. (2018b). STAT3 Roles in Viral Infection: Antiviral or Proviral? Future Virol. 13 (8), 557-574. doi:10.2217/fvl2018-0033

Chen, F., He, D., and Yan, B. (2020). Apigenin Attenuates Allergic Responses of Ovalbumin-Induced Allergic Rhinitis through Modulation of Th1/Th2 Responses in Experimental Mice. Dose Response 18 (1), 1559325820904799. doi:10.1177/1559325820904799

Chen, Z., Sun, X., Shen, S., Zhang, H., Ma, X., Liu, J., et al. (2013). Wedelolactone, a Naturally Occurring Coumestan, Enhances Interferon- $\gamma$ Signaling through Inhibiting STAT1 Protein Dephosphorylation. J. Biol. Chem. 288 (20), 14417-14427. doi:10.1074/jbc.M112.442970

Cheng, C. W., Shieh, P. C., Lin, Y. C., Chen, Y. J., Lin, Y. H., Kuo, D. H., et al. (2010). Indoleamine 2,3-Dioxygenase, an Immunomodulatory Protein, Is Suppressed by (-)-Epigallocatechin-3-Gallate via Blocking of GammaInterferon-Induced JAK-PKC-Delta-STAT1 Signaling in Human Oral Cancer Cells. J. Agric. Food Chem. 58 (2), 887-894. doi:10.1021/jf903377e

Cho, Y. L., Park, J. G., Kang, H. J., Kim, W., Cho, M. J., Jang, J. H., et al. (2019). Ginkgetin, a Biflavone from Ginkgo Biloba Leaves, Prevents Adipogenesis through STAT5-Mediated PPAR $\gamma$ and C/EBPa Regulation. Pharmacol. Res. 139, 325-336. doi:10.1016/j.phrs.2018.11.027

Chung, E. Y., Kim, B. H., Hong, J. T., Lee, C. K., Ahn, B., Nam, S. Y., et al. (2011). Resveratrol Down-Regulates Interferon- $\gamma$-Inducible Inflammatory Genes in Macrophages: Molecular Mechanism via Decreased STAT-1 Activation. J. Nutr. Biochem. 22 (10), 902-909. doi:10.1016/j.jnutbio.2010.07.012

Daryadel, A., Ruiz, P. A., Gehring, N., Stojanovic, D., Ugrica, M., Bettoni, C., et al. (2021). Systemic Jak1 Activation Provokes Hepatic Inflammation and Imbalanced FGF23 Production and Cleavage. FASEB j. 35 (2), e21302. doi:10.1096/fj.202002113R

Dumas, P. Y., Naudin, C., Martin-Lannerée, S., Izac, B., Casetti, L., Mansier, O., et al. (2019). Hematopoietic Niche Drives FLT3-ITD Acute Myeloid Leukemia Resistance to Quizartinib via STAT5-And Hypoxia-Dependent Upregulation of AXL. Haematologica 104 (10), 2017-2027. doi:10.3324/haematol.2018.205385

Elf, S. E. (2021). JAK Out of the Box: Myeloproliferative Neoplasms-Aassociated JAK2 V617F Mutations Contribute to Aortic Aneurysms. Haematologica 106, 1783-1784. doi:10.3324/haematol.2020.277111

Elhennawy, M. G., Abdelaleem, E. A., Zaki, A. A., and Mohamed, W. R. (2021). Cinnamaldehyde and Hesperetin Attenuate TNBS-Induced Ulcerative Colitis in Rats through Modulation of the JAk2/STAT3/SOCS3 Pathway. J. Biochem. Mol. Toxicol. 35, e22730. doi:10.1002/jbt.22730

Gao, F., Wei, D., Bian, T., Xie, P., Zou, J., Mu, H., et al. (2012). Genistein Attenuated Allergic Airway Inflammation by Modulating the Transcription Factors T-Bet, GATA-3 and STAT-6 in a Murine Model of Asthma. Pharmacology 89, 229-236. doi:10.1159/000337180

Garrido-Trigo, A., and Salas, A. (2020). Molecular Structure and Function of Janus Kinases: Implications for the Development of Inhibitors. J. Crohns Colitis 14, S713-S724. doi:10.1093/ecco-jcc/jjz206

Ghaffar, O., Christodoulopoulos, P., Lamkhioued, B., Wright, E., Ihaku, D., Nakamura, Y., et al. (2000). In Vivo expression of Signal Transducer and Activator of Transcription Factor 6 (STAT6) in Nasal Mucosa from Atopic Allergic Rhinitis: Effect of Topical Corticosteroids. Clin. Exp. Allergy 30 (1), 86-93. doi:10.1046/j.1365-2222.2000.00781.x

Gonzalez Suarez, N., Rodriguez Torres, S., Ouanouki, A., El Cheikh-Hussein, L., and Annabi, B. (2021). EGCG Inhibits Adipose-Derived Mesenchymal Stem Cells Differentiation into Adipocytes and Prevents a STAT3-Mediated Paracrine Oncogenic Control of Triple-Negative Breast Cancer Cell Invasive Phenotype. Molecules 26 (6), 1506. doi:10.3390/molecules 26061506

Guan, L. P., and Liu, B. Y. (2016). Antidepressant-Like Effects and Mechanisms of Flavonoids and Related Analogues. Eur. J. Med. Chem. 121, 47-57. doi:10.1016/ j.ejmech.2016.05.026
Hämäläinen, M., Nieminen, R., Vuorela, P., Heinonen, M., and Moilanen, E. (2007). Anti-Inflammatory Effects of Flavonoids: Genistein, Kaempferol, Quercetin, and Daidzein Inhibit STAT-1 and NF-kappaB Activations, whereas Flavone, Isorhamnetin, Naringenin, and Pelargonidin Inhibit Only NF-kappaB Activation along with Their Inhibitory Effect on iNOS Expression and NO Production in Activated Macrophages. Mediators Inflamm. 2007, 45673. doi: $10.1155 / 2007 / 45673$

Hayakawa, F., Sugimoto, K., Harada, Y., Hashimoto, N., Ohi, N., Kurahashi, S. et al. (2013). A Novel STAT Inhibitor, OPB-31121, Has a Significant Antitumor Effect on Leukemia with STAT-Addictive Oncokinases. Blood Cancer J. 3, el66. doi:10.1038/bcj.2013.63

He, L., and Tian, L. (2021). Downregulation of miR-409-3p Suppresses LPSInduced Inflammation in Human Bronchial Epithelial Cells through SOCS3/ JAK1/STAT3 Signaling: The Implication for Bronchopneumonia. Mol. Med. Rep. 23 (3), 190. doi:10.3892/mmr.2021.11829

Hou, S., Yuan, Q., Yu, N., Liu, B., Huang, G., and Yuan, X. (2019). Cardamonin Attenuates Chronic Inflammation and Tumorigenesis in colon. Cell Cycle 18 (23), 3275-3287. doi:10.1080/15384101.2019.1673620

Huang, J. S., Yao, C. J., Chuang, S. E., Yeh, C. T., Lee, L. M., Chen, R. M., et al. (2016). Honokiol Inhibits Sphere Formation and Xenograft Growth of Oral Cancer Side Population Cells Accompanied with JAK/STAT Signaling Pathway Suppression and Apoptosis Induction. BMC cancer 16, 245. doi:10.1186/ s12885-016-2265-6

Huang, X., Dai, S., Dai, J., Xiao, Y., Bai, Y., Chen, B., et al. (2015). Luteolin Decreases Invasiveness, Deactivates STAT3 Signaling, and Reverses Interleukin-6 Induced Epithelial-Mesenchymal Transition and Matrix Metalloproteinase Secretion of Pancreatic Cancer Cells. Onco Targets Ther. 8, 2989-3001. doi:10.2147/ott.S91511

Jeon, Y. J., Jung, S. N., Yun, J., Lee, C. W., Choi, J., Lee, Y. J., et al. (2015). Ginkgetin Inhibits the Growth of DU-145 Prostate Cancer Cells through Inhibition of Signal Transducer and Activator of Transcription 3 Activity. Cancer Sci. 106 (4), 413-420. doi:10.1111/cas.12608

Jung, J. E., Kim, H. S., Lee, C. S., Park, D. H., Kim, Y. N., Lee, M. J., et al. (2007). Caffeic Acid and its Synthetic Derivative CADPE Suppress Tumor Angiogenesis by Blocking STAT3-Mediated VEGF Expression in Human Renal Carcinoma Cells. Carcinogenesis 28 (8), 1780-1787. doi:10.1093/ carcin/bgm130

Kagami, Si., Nakajima, H., Kumano, K., Suzuki, K., Suto, A., Imada, K., et al. (2000). Both stat5a and Stat5b Are Required for Antigen-Induced Eosinophil and T-Cell Recruitment into the Tissue. Blood 95 (4), 1370-1377. doi:10.1182/ blood.v95.4.1370.004k29_1370_1377

Kaufmann, S. H. E., Dorhoi, A., Hotchkiss, R. S., and Bartenschlager, R. (2018). Host-directed Therapies for Bacterial and Viral Infections. Nat. Rev. Drug Discov. 17 (1), 35-56. doi:10.1038/nrd.2017.162

Khan, A. Q., Ahmed, E. I., Elareer, N., Fathima, H., Prabhu, K. S., Siveen, K. S., et al. (2020). Curcumin-Mediated Apoptotic Cell Death in Papillary Thyroid Cancer and Cancer Stem-Like Cells through Targeting of the JAK/STAT3 Signaling Pathway. Int. J. Mol. Sci. 21 (2), 438. doi:10.3390/ ijms2 1020438

Khokra, S., Jyoti, C., Kaushik, P., Alam, M. M., Zaman, S., Ahmad, A., et al. (2016). Quinoline Based Furanones and Their Nitrogen Analogues: Docking, Synthesis and Biological Evaluation. Saudi Pharm. J. 24 (6), 705-717. doi:10.1016/ j.jsps.2015.05.002

Kim, B. H., Na, K. M., Oh, I., Song, I. H., Lee, Y. S., Shin, J., et al. (2013). Kurarinone Regulates Immune Responses through Regulation of the JAK/STAT and TCRMediated Signaling Pathways. Biochem. Pharmacol. 85 (8), 1134-1144. doi:10.1016/j.bcp.2013.01.005

Kim, B. S., Howell, M. D., Sun, K., Papp, K., Nasir, A., and Kuligowski, M. E. (2020). Treatment of Atopic Dermatitis with Ruxolitinib Cream (JAK1/JAK2 Inhibitor) or Triamcinolone Cream. J. Allergy Clin. Immunol. 145 (2), 572-582. doi:10.1016/j.jaci.2019.08.042

Kim, C., Lee, S. G., Yang, W. M., Arfuso, F., Um, J. Y., Kumar, A. P., et al. (2018) Formononetin-induced Oxidative Stress Abrogates the Activation of STAT3/5 Signaling axis and Suppresses the Tumor Growth in Multiple Myeloma Preclinical Model. Cancer Lett. 431, 123-141. doi:10.1016/j.canlet.2018.05.038

Kofoed, E. M., Hwa, V., Little, B., Woods, K. A., Buckway, C. K., Tsubaki, J., et al. (2003). Growth Hormone Insensitivity Associated with a STAT5b Mutation. N. Engl. J. Med. 349 (12), 1139-1147. doi:10.1056/NEJMoa022926 
Korman, B. D., Kastner, D. L., Gregersen, P. K., and Remmers, E. F. (2008). STAT4: Genetics, Mechanisms, and Implications for Autoimmunity. Curr. Allergy Asthma Rep. 8 (5), 398-403. doi:10.1007/s11882-008-0077-8

Kurdi, M., Sivakumaran, V., Duhé, R. J., Aon, M. A., Paolocci, N., and Booz, G. W. (2012). Depletion of Cellular Glutathione Modulates LIF-Induced JAK1STAT3 Signaling in Cardiac Myocytes. Int. J. Biochem. Cel Biol. 44 (12), 2106-2115. doi:10.1016/j.biocel.2012.08.016

Lee, J. H., Kim, C., Ko, J. H., Jung, Y. Y., Jung, S. H., Kim, E., et al. (2019). Casticin Inhibits Growth and Enhances Ionizing Radiation-Induced Apoptosis through the Suppression of STAT3 Signaling cascade. J. Cel Biochem. 120 (6), 9787-9798. doi:10.1002/jcb.28259

Lee, S. B., Shin, J. S., Han, H. S., Lee, H. H., Park, J. C., and Lee, K. T. (2018). Kaempferol 7-O- $\beta$-D-Glucoside Isolated from the Leaves of Cudrania Tricuspidata Inhibits LPS-Induced Expression of Pro-inflammatory Mediators through Inactivation of NF-Kb, AP-1, and JAK-STAT in RAW 264.7 Macrophages. Chem. Biol. Interact 284, 101-111. doi:10.1016/ j.cbi.2018.02.022

Lee, S. W., Yun, B. R., Kim, M. H., Park, C. S., Lee, W. S., Oh, H. M., et al. (2012). Phenolic Compounds Isolated from Psoralea Corylifolia Inhibit IL-6-Induced STAT3 Activation. Planta Med. 78 (9), 903-906. doi:10.1055/s-0031-1298482

Leopold, J. A. (2021). Inhibiting Jak2 Ameliorates Pulmonary Hypertension: Fulfilling the Promise of Precision Medicine. Am. J. Respir. Cel Mol. Biol. 64 (1), 12-13. doi:10.1165/rcmb.2020-0384ED

Li, C., Zhu, M., Zhu, J., Lu, Q., Shi, B., Sun, B., et al. (2021). SOX12 Contributes to the Activation of the JAK2/STAT3 Pathway and Malignant Transformation of Esophageal Squamous Cell Carcinoma. Oncol. Rep. 45 (1), 129-138. doi:10.3892/or.2020.7863

Li, G., Ding, K., Qiao, Y., Zhang, L., Zheng, L., Pan, T., et al. (2020a). Flavonoids Regulate Inflammation and Oxidative Stress in Cancer. Molecules 25 (23), 5628. doi:10.3390/molecules25235628

Li, P. G., Xu, J. W., Ikeda, K., Kobayakawa, A., Kayano, Y., Mitani, T., et al. (2005). Caffeic Acid Inhibits Vascular Smooth Muscle Cell Proliferation Induced by Angiotensin II in Stroke-Prone Spontaneously Hypertensive Rats. Hypertens. Res. 28 (4), 369-377. doi:10.1291/hypres.28.369

Li, S. B., Liu, Y. Y., Yuan, L., Ji, M. F., Zhang, A., Li, H. Y., et al. (2020b). Autocrine INSL5 Promotes Tumor Progression and Glycolysis via Activation of STAT5 Signaling. EMBO Mol. Med. 12 (9), e12050. doi:10.15252/emmm.202012050

Li, T., Zhao, X., Mo, Z., Huang, W., Yan, H., Ling, Z., et al. (2014). Formononetin Promotes Cell Cycle Arrest via Downregulation of Akt/Cyclin D1/CDK4 in Human Prostate Cancer Cells. Cell Physiol. Biochem. 34 (4), 1351-1358. doi:10.1159/000366342

Li, Z., and Chen, J. (2021). miR-583 Inhibits the Proliferation and Invasion of Prostate Cancer Cells by Targeting JAK1. Mol. Med. Rep. 23 (3), 199. doi: 10.3892/mmr.2021.11838

Luo, J., Wang, A., Zhen, W., Wang, Y., Si, H., Jia, Z., et al. (2018). Phytonutrient Genistein Is a Survival Factor for Pancreatic $\beta$-Cells via GPR30-Mediated Mechanism. J. Nutr. Biochem. 58, 59-70. doi:10.1016/j.jnutbio.2018.04.018

Maeda, Y., Takahashi, H., Nakai, N., Yanagita, T., Ando, N., Okubo, T., et al. (2018). Apigenin Induces Apoptosis by Suppressing Bcl-Xl and Mcl-1 Simultaneously via Signal Transducer and Activator of Transcription 3 Signaling in Colon Cancer. Int. J. Oncol. 52 (5), 1661-1673. doi:10.3892/ ijo. 2018.4308

Mahapatra, D. K., Bharti, S. K., and Asati, V. (2015). Anti-Cancer Chalcones: Structural and Molecular Target Perspectives. Eur. J. Med. Chem. 98, 69-114. doi:10.1016/j.ejmech.2015.05.004

Mahmoud, A. M., and Abd El-Twab, S. M. (2017). Caffeic Acid Phenethyl Ester Protects the Brain against Hexavalent Chromium Toxicity by Enhancing Endogenous Antioxidants and Modulating the JAK/STAT Signaling Pathway. Biomed. Pharmacother. 91, 303-311. doi:10.1016/j.biopha.2017.04.073

Minegishi, Y., Saito, M., Morio, T., Watanabe, K., Agematsu, K., Tsuchiya, S., et al. (2006). Human Tyrosine Kinase 2 Deficiency Reveals its Requisite Roles in Multiple Cytokine Signals Involved in Innate and Acquired Immunity. Immunity 25 (5), 745-755. doi:10.1016/j.immuni.2006.09.009

Moens, L., Van Eyck, L., Jochmans, D., Mitera, T., Frans, G., Bossuyt, X., et al. (2017). A Novel kindred with Inherited STAT2 Deficiency and Severe Viral Illness. J. Allergy Clin. Immunol. 139 (6), 1995-1997. doi:10.1016/ j.jaci.2016.10.033
Mohr, A., Fahrenkamp, D., Rinis, N., and Müller-Newen, G. (2013). DominantNegative Activity of the STAT3-Y705f Mutant Depends on the N-Terminal Domain. Cell Commun Signal 11, 83. doi:10.1186/1478-811x-11-83

Muthian, G., and Bright, J. J. (2004). Quercetin, a Flavonoid Phytoestrogen, Ameliorates Experimental Allergic Encephalomyelitis by Blocking IL-12 Signaling through JAK-STAT Pathway in T Lymphocyte. J. Clin. Immunol. 24 (5), 542-552. doi:10.1023/B:JOCI.0000040925.55682.a5

Ni, Y., Zhao, S., Yin, X., Wang, H., Guang, Q., Hu, G., et al. (2017). Intravesicular Administration of Sodium Hyaluronate Ameliorates the Inflammation and Cell Proliferation of Cystitis Cystica et Glandularis Involving Interleukin-6/JAK2/ Stat3 Signaling Pathway. Sci. Rep. 7 (1), 15892. doi:10.1038/s41598-01716088-9

Noguchi, S., Nakaseko, C., Nishiwaki, K., Ogasawara, H., Ohishi, K., Tokuhira, M., et al. (2018). Switching to Nilotinib Is Associated with Deeper Molecular Responses in Chronic Myeloid Leukemia Chronic Phase with Major Molecular Responses to Imatinib: STAT1 Trial in Japan. Int. J. Hematol. 108 (2), 176-183. doi:10.1007/s12185-018-2459-6

O'Shea, J. J., Holland, S. M., and Staudt, L. M. (2013). JAKs and STATs in Immunity, Immunodeficiency, and Cancer. N. Engl. J. Med. 368 (2), 161-170. doi:10.1056/NEJMra1202117

O'Shea, J. J., Schwartz, D. M., Villarino, A. V., Gadina, M., McInnes, I. B., and Laurence, A. (2015). The JAK-STAT Pathway: Impact on Human Disease and Therapeutic Intervention. Annu. Rev. Med. 66, 311-328. doi:10.1146/annurevmed-051113-024537

Ozbey, U., Attar, R., Romero, M. A., Alhewairini, S. S., Afshar, B., Sabitaliyevich, U. Y., et al. (2018). Apigenin as an Effective Anticancer Natural Product: Spotlight on TRAIL, WNT/ $\beta$-catenin, JAK-STAT Pathways, and microRNAs. J. Cel Biochem. 120, 1060-1067. doi:10.1002/jcb.27575

Padmavathi, G., Roy, N. K., Bordoloi, D., Arfuso, F., Mishra, S., Sethi, G., et al. (2017). Butein in Health and Disease: A Comprehensive Review. Phytomedicine 25, 118-127. doi:10.1016/j.phymed.2016.12.002

Pandey, M. K., Sung, B., Ahn, K. S., and Aggarwal, B. B. (2009). Butein Suppresses Constitutive and Inducible Signal Transducer and Activator of Transcription (STAT) 3 Activation and STAT3-Regulated Gene Products through the Induction of a Protein Tyrosine Phosphatase SHP-1. Mol. Pharmacol. 75 (3), 525-533. doi:10.1124/mol.108.052548

Patel, Z. H., Lu, X., Miller, D., Forney, C. R., Lee, J., Lynch, A., et al. (2018). A Plausibly Causal Functional Lupus-Associated Risk Variant in the STAT1STAT4 Locus. Hum. Mol. Genet. 27 (13), 2392-2404. doi:10.1093/hmg/ ddy 140

Pinheiro, D. M. L., de Oliveira, A. H. S., Coutinho, L. G., Fontes, F. L., de Medeiros Oliveira, R. K., Oliveira, T. T., et al. (2019). Resveratrol Decreases the Expression of Genes Involved in Inflammation through Transcriptional Regulation. Free Radic. Biol. Med. 130, 8-22. doi:10.1016/ j.freeradbiomed.2018.10.432

Pinz, S., Unser, S., Brueggemann, S., Besl, E., Al-Rifai, N., Petkes, H., et al. (2014). The Synthetic a-Bromo-2',3,4,4'-tetramethoxychalcone (a-Br-TMC) Inhibits the JAK/STAT Signaling Pathway. PloS one 9 (3), e90275. doi:10.1371/ journal.pone.0090275

Ramalingam, S., Ramamurthy, V. P., and Njar, V. C. O. (2017). Dissecting Major Signaling Pathways in Prostate Cancer Development and Progression: Mechanisms and Novel Therapeutic Targets. J. Steroid Biochem. Mol. Biol. 166, 16-27. doi:10.1016/j.jsbmb.2016.07.006

Reddy, V., and Cohen, S. (2020). JAK Inhibitors: What Is New? Curr. Rheumatol. Rep. 22 (9), 50. doi:10.1007/s11926-020-00931-6

Reilley, M. J., McCoon, P., Cook, C., Lyne, P., Kurzrock, R., Kim, Y., et al. (2018). STAT3 Antisense Oligonucleotide AZD9150 in a Subset of Patients with Heavily Pretreated Lymphoma: Results of a Phase 1b Trial. J. Immunother. Cancer 6 (1), 119. doi:10.1186/s40425-018-0436-5

Ren, D. Y., Xu, T., Li, R., Huang, C., Huang, Y., Li, R. Q., et al. (2013). 5,7,3'Triacetyl Hesperetin Suppresses Adjuvant-Induced Arthritis in Rats through Modulating JAK2/STAT3 Pathway. Am. J. Chin. Med. 41 (3), 601-614. doi:10.1142/s0192415x13500420

Schroeder, M. A., Khoury, H. J., Jagasia, M., Ali, H., Schiller, G. J., Staser, K., et al. (2020). A Phase 1 Trial of Itacitinib, a Selective JAK1 Inhibitor, in Patients with Acute Graft-Versus-Host Disease. Blood Adv. 4 (8), 1656-1669. doi:10.1182/ bloodadvances. 2019001043 
Schwartz, D. M., Bonelli, M., Gadina, M., and O’Shea, J. J. (2016). Type I/II Cytokines, JAKs, and New Strategies for Treating Autoimmune Diseases. Nat. Rev. Rheumatol. 12 (1), 25-36. doi:10.1038/nrrheum.2015.167

Senggunprai, L., Kukongviriyapan, V., Prawan, A., and Kukongviriyapan, U. (2014). Quercetin and EGCG Exhibit Chemopreventive Effects in Cholangiocarcinoma Cells via Suppression of JAK/STAT Signaling Pathway. Phytother Res. 28 (6), 841-848. doi:10.1002/ptr.5061

Sengupta, S., Nagalingam, A., Muniraj, N., Bonner, M. Y., Mistriotis, P., Afthinos, A., et al. (2017). Activation of Tumor Suppressor LKB1 by Honokiol Abrogates Cancer Stem-Like Phenotype in Breast Cancer via Inhibition of Oncogenic Stat3. Oncogene 36 (41), 5709-5721. doi:10.1038/onc.2017.164

Shuai, K. (2000). Modulation of STAT Signaling by STAT-Interacting Proteins. Oncogene 19 (21), 2638-2644. doi:10.1038/sj.onc.1203522

Song, S., Su, Z., Xu, H., Niu, M., Chen, X., Min, H., et al. (2017a). Luteolin Selectively Kills STAT3 Highly Activated Gastric Cancer Cells through Enhancing the Binding of STAT3 to SHP-1. Cell Death Dis. 8 (2), e2612. doi:10.1038/cddis.2017.38

Song, X. L., Zhang, Y. J., Wang, X. F., Zhang, W. J., Wang, Z., Zhang, F., et al. (2017b). Casticin Induces Apoptosis and G0/G1 Cell Cycle Arrest in Gallbladder Cancer Cells. Cancer Cel Int 17, 9. doi:10.1186/s12935-016$0377-3$

Soundharrajan, I., Kim, D. H., Kuppusamy, P., and Choi, K. C. (2019). Modulation of Osteogenic and Myogenic Differentiation by a Phytoestrogen Formononetin via p38MAPK-dependent JAK-STAT and Smad-1/5/8 Signaling Pathways in Mouse Myogenic Progenitor Cells. Sci. Rep. 9 (1), 9307. doi:10.1038/s41598019-45793-w

Stokes, B. A., Yadav, S., Shokal, U., Smith, L. C., and Eleftherianos, I. (2015). Bacterial and Fungal Pattern Recognition Receptors in Homologous Innate Signaling Pathways of Insects and Mammals. Front. Microbiol. 6, 19. doi:10.3389/fmicb.2015.00019

Sun, L. R., Zhou, W., Zhang, H. M., Guo, Q. S., Yang, W., Li, B. J., et al. (2019a). Modulation of Multiple Signaling Pathways of the Plant-Derived Natural Products in Cancer. Front. Oncol. 9, 1153. doi:10.3389/ fonc.2019.01153

Sun, Y., Liu, L., Wang, Y., He, A., Hu, H., Zhang, J., et al. (2019b). Curcumin Inhibits the Proliferation and Invasion of MG-63 Cells through Inactivation of the P-JAK2/p-STAT3 Pathway. Onco Targets Ther. 12, 2011-2021. doi:10.2147/ ott.S172909

Surbek, M., Tse, W., Moriggl, R., and Han, X. (2021). A Centric View of JAK/ STAT5 in Intestinal Homeostasis, Infection, and Inflammation. Cytokine 139, 155392. doi:10.1016/j.cyto.2020.155392

Svrlanska, A., Ruhland, A., Marschall, M., Reuter, N., and Stamminger, T. (2020). Wedelolactone Inhibits Human Cytomegalovirus Replication by Targeting Distinct Steps of the Viral Replication Cycle. Antivir. Res 174, 104677. doi:10.1016/j.antiviral.2019.104677

Takahashi, A., Yamamoto, N., and Murakami, A. (2011). Cardamonin Suppresses Nitric Oxide Production via Blocking the IFN- $\gamma /$ STAT Pathway in EndotoxinChallenged Peritoneal Macrophages of ICR Mice. Life Sci. 89, 337-342. doi:10.1016/j.lfs.2011.06.027

Takahashi, N., Nishiwaki, K., Nakaseko, C., Aotsuka, N., Sano, K., Ohwada, C., et al. (2018). Treatment-Free Remission after Two-Year Consolidation Therapy with Nilotinib in Patients with Chronic Myeloid Leukemia: STAT2 Trial in Japan. Haematologica 103 (11), 1835-1842. doi:10.3324/haematol.2018.194894

Takeda, T., Tsubaki, M., Tomonari, Y., Kawashima, K., Itoh, T., Imano, M., et al. (2018). Bavachin Induces the Apoptosis of Multiple Myeloma Cell Lines by Inhibiting the Activation of Nuclear Factor Kappa B and Signal Transducer and Activator of Transcription 3. Biomed. Pharmacother. 100, 486-494. doi:10.1016/j.biopha.2018.02.019

Tay, K. C., Tan, L. T., Chan, C. K., Hong, S. L., Chan, K. G., Yap, W. H., et al. (2019). Formononetin: A Review of its Anticancer Potentials and Mechanisms. Front. Pharmacol. 10, 820. doi:10.3389/fphar.2019.00820

Tefferi, A. (2008). JAK and MPL Mutations in Myeloid Malignancies. Leuk. Lymphoma 49 (3), 388-397. doi:10.1080/10428190801895360

Tian, Y. H., Kim, H. C., Cui, J. M., and Kim, Y. C. (2005). Hepatoprotective Constituents of Cudrania Tricuspidata. Arch. Pharm. Res. 28 (1), 44-48. doi:10.1007/bf02975134

Tuttle, K. R., Brosius, F. C., Adler, S. G., Kretzler, M., Mehta, R. L., Tumlin, J. A., et al. (2018). JAK1/JAK2 Inhibition by Baricitinib in Diabetic Kidney Disease:
Results from a Phase 2 Randomized Controlled Clinical Trial. Nephrol. Dial. Transpl. 33 (11), 1950-1959. doi:10.1093/ndt/gfx377

Tyagi, A., Singh, R. P., Ramasamy, K., Raina, K., Redente, E. F., Dwyer-Nield, L. D., et al. (2009). Growth Inhibition and Regression of Lung Tumors by Silibinin: Modulation of Angiogenesis by Macrophage-Associated Cytokines and Nuclear Factor-kappaB and Signal Transducers and Activators of Transcription 3. Cancer Prev. Res. (Phila) 2 (1), 74-83. doi:10.1158/1940-6207.Capr-08-0095

Ungureanu, D., Saharinen, P., Junttila, I., Hilton, D. J., and Silvennoinen, O. (2002). Regulation of Jak2 through the Ubiquitin-Proteasome Pathway Involves Phosphorylation of Jak2 on Y1007 and Interaction with SOCS-1. Mol. Cel Biol. 22 (10), 3316-3326. doi:10.1128/mcb.22.10.3316-3326.2002

Van Den Neste, E., André, M., Gastinne, T., Stamatoullas, A., Haioun, C., Belhabri, A., et al. (2018). A Phase II Study of the Oral JAK1/JAK2 Inhibitor Ruxolitinib in Advanced Relapsed/Refractory Hodgkin Lymphoma. Haematologica 103 (5), 840-848. doi:10.3324/haematol.2017.180554

Villarino, A. V., Gadina, M., O’Shea, J. J., and Kanno, Y. (2020). SnapShot: JakSTAT Signaling II. Cell 181 (7), 1696. doi:10.1016/j.cell.2020.04.052

Virtanen, A. T., Haikarainen, T., Raivola, J., and Silvennoinen, O. (2019). Selective JAKinibs: Prospects in Inflammatory and Autoimmune Diseases. BioDrugs 33 (1), 15-32. doi:10.1007/s40259-019-00333-w

Wang, A. L., Li, Y., Zhao, Q., and Fan, L. Q. (2018). Formononetin Inhibits colon Carcinoma Cell Growth and Invasion by microRNA-149-Mediated EphB3 Downregulation and Inhibition of PI3K/AKT and STAT3 Signaling Pathways. Mol. Med. Rep. 17 (6), 7721-7729. doi:10.3892/mmr.2018.8857

Wang, X., Xue, X., Wang, H., Xu, F., Xin, Z., Wang, K., et al. (2020). Quercetin Inhibits Human Microvascular Endothelial Cells Viability, Migration and Tube-Formation In vitro through Restraining microRNA-216a. J. Drug Target. 28 (6), 609-616. doi:10.1080/1061186x.2019.1700263

Wang, Y., Quan, F., Cao, Q., Lin, Y., Yue, C., Bi, R., et al. (2021). Quercetin Alleviates Acute Kidney Injury by Inhibiting Ferroptosis. J. Adv. Res. 28, 231-243. doi:10.1016/j.jare.2020.07.007

Westhovens, R., Taylor, P. C., Alten, R., Pavlova, D., Enríquez-Sosa, F., Mazur, M., et al. (2017). Filgotinib (GLPG0634/GS-6034), an Oral JAK1 Selective Inhibitor, Is Effective in Combination with Methotrexate (MTX) in Patients with Active Rheumatoid Arthritis and Insufficient Response to MTX: Results from a Randomised, Dose-Finding Study (DARWIN 1). Ann. Rheum. Dis. 76 (6), 998-1008. doi:10.1136/annrheumdis-2016-210104

Wu, N., Liu, J., Zhao, X., Yan, Z., Jiang, B., Wang, L., et al. (2015). Cardamonin Induces Apoptosis by Suppressing STAT3 Signaling Pathway in Glioblastoma Stem Cells. Tumour Biol. 36 (12), 9667-9676. doi:10.1007/s13277-015-3673-y

Wu, S. F., Chang, C. B., Hsu, J. M., Lu, M. C., Lai, N. S., Li, C., et al. (2017). Hydroxychloroquine Inhibits CD154 Expression in CD4+ T Lymphocytes of Systemic Lupus Erythematosus through NFAT, but Not STAT5, Signaling. Arthritis Res. Ther. 19 (1), 183. doi:10.1186/s13075-017-1393-y

Xie, X., Wang, X., Shi, X., Zhang, Y., Laster, K. V., Liu, K., et al. (2021). Anwulignan Is a Novel JAK1 Inhibitor that Suppresses Non-small Cell Lung Cancer Growth. J. Cel Mol. Med. 25, 2645-2654. doi:10.1111/jcmm.16289

Xie, Z. H., Quan, M. F., Liu, F., Cao, J. G., and Zhang, J. S. (2011). 5-allyl-7-GenDifluoromethoxychrysin Enhances TRAIL-Induced Apoptosis in Human Lung Carcinoma A549 Cells. BMC cancer 11, 322. doi:10.1186/1471-2407-11-322

Xin, P., Xu, X., Deng, C., Liu, S., Wang, Y., Zhou, X., et al. (2020). The Role of JAK/ STAT Signaling Pathway and its Inhibitors in Diseases. Int. Immunopharmacol 80, 106210. doi:10.1016/j.intimp.2020.106210

Xiong, M., Wang, L., Yu, H. L., Han, H., Mao, D., Chen, J., et al. (2016). Ginkgetin Exerts Growth Inhibitory and Apoptotic Effects on Osteosarcoma Cells through Inhibition of STAT3 and Activation of Caspase-3/9. Oncol. Rep. 35 (2), 1034-1040. doi:10.3892/or.2015.4427

Xu, D., Liang, J., Lin, J., and Yu, C. (2019). PKM2: A Potential Regulator of Rheumatoid Arthritis via Glycolytic and Non-Glycolytic Pathways. Front. Immunol. 10, 2919. doi:10.3389/fimmu.2019.02919

Xu, Y., Wang, W., Tian, Y., Liu, J., and Yang, R. (2016). Polymorphisms in STAT4 and IRF5 Increase the Risk of Systemic Sclerosis: a Meta-Analysis. Int. J. Dermatol. 55 (4), 408-416. doi:10.1111/ijd.12839

Yang, C., Mai, H., Peng, J., Zhou, B., Hou, J., and Jiang, D. (2020a). STAT4: An Immunoregulator Contributing to Diverse Human Diseases. Int. J. Biol. Sci. 16 (9), 1575-1585. doi:10.7150/ijbs.41852

Yang, C. L., Liu, Y. Y., Ma, Y. G., Xue, Y. X., Liu, D. G., Ren, Y., et al. (2012). Curcumin Blocks Small Cell Lung Cancer Cells Migration, Invasion, 
Angiogenesis, Cell Cycle and Neoplasia through Janus Kinase-STAT3 Signalling Pathway. PloS one 7 (5), e37960. doi:10.1371/journal.pone.0037960

Yang, M. Y., Wang, C. J., Chen, N. F., Ho, W. H., Lu, F. J., and Tseng, T. H. (2014). Luteolin Enhances Paclitaxel-Induced Apoptosis in Human Breast Cancer MDA-MB-231 Cells by Blocking STAT3. Chem. Biol. Interact 213, 60-68. doi:10.1016/j.cbi.2014.02.002

Yang, S. H., Lee, K. S., Kim, I. S., Hong, J. T., Sung, J. H., Son, B. C., et al. (2009). Long-term Survival in Primary CNS Lymphoma Treated by High-Dose Methotrexate Monochemotherapy: Role of STAT6 Activation as Prognostic Determinant. J. Neurooncol. 92 (1), 65-71. doi:10.1007/s11060008-9736-9

Yang, X., Chang, Y., and Wei, W. (2020b). Emerging Role of Targeting Macrophages in Rheumatoid Arthritis: Focus on Polarization, Metabolism and Apoptosis. Cell Prolif 53 (7), e12854. doi:10.1111/cpr.12854

Yi, J., Li, S., Wang, C., Cao, N., Qu, H., Cheng, C., et al. (2019). Potential Applications of Polyphenols on Main ncRNAs Regulations as Novel Therapeutic Strategy for Cancer. Biomed. Pharmacother. 113, 108703. doi:10.1016/j.biopha.2019.108703

Yuan, K., Ye, J., Liu, Z., Ren, Y., He, W., Xu, J., et al. (2020). Complement C3 Overexpression Activates JAK2/STAT3 Pathway and Correlates with Gastric Cancer Progression. J. Exp. Clin. Cancer Res. 39 (1), 9. doi:10.1186/s13046-0191514-3

Zakaryan, H., Arabyan, E., Oo, A., and Zandi, K. (2017). Flavonoids: Promising Natural Compounds against Viral Infections. Arch. Virol. 162 (9), 2539-2551. doi:10.1007/s00705-017-3417-y

Zhang, L. L., Pan, H. X., Wang, Y. X., Guo, T., and Liu, L. (2019). Genome Profiling Revealed the Activation of IL2RG/JAK3/STAT5 in Peripheral T-Cell Lymphoma Expressing the ITK-SYK Fusion Gene. Int. J. Oncol. 55 (5), 1077-1089. doi:10.3892/ijo.2019.4882

Zhang, X., Wu, J., Ye, B., Wang, Q., Xie, X., and Shen, H. (2016). Protective Effect of Curcumin on TNBS-Induced Intestinal Inflammation Is Mediated through the JAK/STAT Pathway. BMC Complement. Altern. Med. 16 (1), 299. doi:10.1186/ s12906-016-1273-z
Zhang, Z., Ye, T., Cai, X., Yang, J., Lu, W., Hu, C., et al. (2013). 5,7Dihydroxyflavone Enhances the Apoptosis-Inducing Potential of TRAIL in Human Tumor Cells via Regulation of Apoptosis-Related Proteins. EvidenceBased Complement. Altern. Med. 2013, 1-13. doi:10.1155/2013/434709

Zhao, F., Ci, X., Man, X., Li, J., Wei, Z., and Zhang, S. (2021). Food-Derived Pharmacological Modulators of the Nrf2/ARE Pathway: Their Role in the Treatment of Diseases. Molecules 26 (4), 1016. doi:10.3390/molecules26041016

Zheng, J., van de Veerdonk, F. L., Crossland, K. L., Smeekens, S. P., Chan, C. M., A Shehri, T., et al. (2015). Gain-of-Function STAT1 Mutations Impair STAT3 Activity in Patients with Chronic Mucocutaneous Candidiasis (CMC). Eur. J. Immunol. 45 (10), 2834-2846. doi:10.1002/eji.201445344

Zhou, Z., Zhou, X., Dong, Y., Li, M., and Xu, Y. (2019). Formononetin Ameliorates High Glucose-Induced Endothelial Dysfunction by Inhibiting the JAK/STAT Signaling Pathway. Mol. Med. Rep. 20 (3), 2893-2901. doi:10.3892/ mmr.2019.10512

Conflict of Interest: The authors declare that the research was conducted in the absence of any commercial or financial relationships that could be construed as a potential conflict of interest.

Publisher's Note: All claims expressed in this article are solely those of the authors and do not necessarily represent those of their affiliated organizations, or those of the publisher, the editors and the reviewers. Any product that may be evaluated in this article, or claim that may be made by its manufacturer, is not guaranteed or endorsed by the publisher.

Copyright (C) 2021 Yin, Wang, Yu, Chen, Zhu and Sun. This is an open-access article distributed under the terms of the Creative Commons Attribution License (CC BY). The use, distribution or reproduction in other forums is permitted, provided the original author(s) and the copyright owner(s) are credited and that the original publication in this journal is cited, in accordance with accepted academic practice. No use, distribution or reproduction is permitted which does not comply with these terms. 


\section{GLOSSARY}

Ang II angiotensin II

CA caffeic acid

CAPE caffeic acid phenethy lester

C/EBPa CCAAT/ enhancer binding protein a

EGCG Epigallocatechin-3-gallate

EAE experimental autoimmune encephalomyelitis

EGF epidermal growth factor

EMT epithelial-mesenchymal transition

FN Formononetin

GH growth hormone

GK Ginkgetin

GM-CSF granulocyte-macrophage colony-stimulating factor GOF Gain-of-function

HMEC-1 human microvascular endothelial cells

IFNs interferons

IL interleukins

iNOS inducible nitric oxide synthase

JAK janus kinase

JH JAK homology

LKB1 Liver kinase B1
LOF Loss-of-function

LPS lipopolysaccharide

MMP matrix metalloproteinase

NLF Nasal lavage fluid

NSCLC non-small-cell lung carcinoma

OVA ovalbumin

PDGF platelet-derived growth factor

PIAS protein inhibitors of activated STATs

p-JAK2 phosphorylated JAK2

PPAR $\gamma$ peroxisomal proliferation-activated receptor $\gamma$

PSA psoriatic arthritis

p-STAT3 phosphorylated STAT3

PTPs protein tyrosine phosphatases

RA rheumatoid arthritis

SH2 the Src-homology type 2

SHP-1 Src homology region 2 domain-containing phosphatase 1

SOCS suppressor of cytokine signaling

STAT signal transducer and activator of transcription

TAHP 5,7,3'-triacetyl hesperetin

T-bet T-box transcription factor

TCPTP T-cell protein tyrosine phosphatase

VEGF Vascular Endothelial Growth Factor 